\title{
Monolignol acylation and lignin structure in some nonwoody plants: A 2D NMR study
}

\author{
Ángel T. Martínez ${ }^{\mathrm{a}, *}$, Jorge Rencoret ${ }^{\mathrm{b}}$, Gisela Marques ${ }^{\mathrm{b}}$, Ana Gutiérrez ${ }^{\mathrm{b}}$, David Ibarra ${ }^{\mathrm{a}, 1}$, \\ Jesús Jiménez-Barbero ${ }^{a}$, José C. del Río ${ }^{\mathrm{b}}$ \\ ${ }^{a}$ Centro de Investigaciones Biológicas, CSIC, Ramiro de Maeztu 9, E-28040 Madrid, Spain \\ ${ }^{\mathrm{b}}$ Instituto de Recursos Naturales y Agrobiología de Sevilla, CSIC, P.O. Box 1052, E-41080 Seville, Spain
}

\section{A R T I C L E I N F O}

\section{Article history:}

Received 14 June 2008

Received in revised form 28 August 2008

Available online 20 October 2008

\section{Keywords:}

Agave sisalana

Cannabis sativa

Musa textilis

2D NMR

HSQC

Lignin structure

Acetic acid esters

p-Coumaric acid esters

Lignification, Monolignols

Resinols

Etherified lignin

$\mathrm{H}: \mathrm{G}: \mathrm{S}$ ratio

Milled-wood-lignin

\begin{abstract}
A B S T R A C T
Lignins from three nonwoody angiosperms were analyzed by 2D NMR revealing important differences in their molecular structures. The Musa textilis milled-wood-lignin (MWL), with a syringyl-to-guaiacyl $(\mathrm{S} / \mathrm{G})$ ratio of 9 , was strongly acylated (near $85 \%$ of side-chains) at the $\gamma$-carbon by both acetates and $p$-coumarates, as estimated from ${ }^{1} \mathrm{H}_{-}{ }^{13} \mathrm{C}$ correlations in $\mathrm{C}_{\gamma}$-esterified and $\mathrm{C}_{\gamma}$-OH units. The $p$-coumarate $\mathrm{H}_{3,5}-\mathrm{C}_{3,5}$ correlation signal was completely displaced by acetylation, and disappeared after alkali treatment, indicating that $p$-coumaric acid was esterified maintaining its free phenolic group. By contrast, the Cannabis sativa MWL ( $/ \mathrm{G} \sim 0.8$ ) was free of acylating groups, and the Agave sisalana MWL $(\mathrm{S} / \mathrm{G} \sim 4$ ) showed high acylation degree (near $80 \%$ ) but exclusively with acetates. Extensive $C_{\gamma}$-acylation results in the absence (in M. textilis lignin) or low abundance ( $4 \%$ in A. sisalana lignin) of $\beta-\beta^{\prime}$ resinol linkages, which require free $\mathrm{C}_{\gamma}-\mathrm{OH}$ to form the double tetrahydrofuran ring. However, minor signals revealed unusual acylated $\beta-\beta^{\prime}$ structures confirming that acylation is produced at the monolignol level, in agreement with chromatographic identification of $\gamma$-acetylated sinapyl alcohol among the plant extractives. In contrast, resinol substructures involved $22 \%$ side-chains in the $C$. sativa MWL. The ratio between $\beta-\beta^{\prime}$ and $\beta-O-4^{\prime}$ sidechains in these and other MWL varied from 0.32 in C. sativa MWL to 0.02 in M. textilis MWL, and was inversely correlated with the degree of acylation. The opposite was observed for the $S / G$ ratio that was directly correlated with the acylation degree. Monolignol acylation is discussed as a mechanism potentially involved in the control of lignin structure.
\end{abstract}

(c) 2008 Elsevier Ltd. All rights reserved.

\section{Introduction}

Lignin is generally considered as formed by the dehydrogenative polymerization of three $p$-hydroxycinnamyl alcohol precursors (Fig. 1): $p$-coumaryl (1), coniferyl (2) and sinapyl (3) alcohols (Boerjan et al., 2003; Fengel and Wegener, 1984; Higuchi, 1997). Each of these monolignols gives rise to a different type of lignin unit called $\mathrm{H}$ ( $p$-hydroxyphenyl), $\mathrm{G}$ (guaiacyl) and S (syringyl) units, respectively. The dehydrogenation reaction is initiated by one-electron oxidation of the phenolic monolignols to their phenoxy radicals by plant cell-wall peroxidases and maybe also laccases. Then, it proceeds by radical coupling between specific positions of two phenoxy radicals, corresponding to their resonant forms, and gives rise to different carbon-carbon and ether linkages. The resulting quinone methides rearomatize by water addition or by reaction with neigh-

\footnotetext{
* Corresponding author. Tel.: +34 918373112; fax: +34 915360432.

E-mail address: ATMartinez@cib.csic.es (Á.T. Martínez).

1 Present address: Department of Fibre and Polymer Technology, Royal Institute of Technology (KTH), SE-100 44 Stockholm, Sweden.
}

bor nucleophiles forming the different dilignols (including $\beta-O-4^{\prime}$, phenylcoumaran and resinols, among others). Polymerization progress requires new activation of both a monolignol molecule and the growing lignin polymer for subsequent radical coupling, which is mainly produced by an end-wise reaction. However, chain branching can also be produced due to the existence of some $5-0-4^{\prime}$ or $5-5^{\prime}$ linkages leaving a free phenolic unit that can be oxidized again giving rise to a second (e.g. 4-O- $\beta^{\prime \prime}$ ) inter-unit linkage.

Recently, a relatively large number of other phenolic compounds (alcohols, aldehydes, acids, esters and amides) have been reported to act as lignin precursors, to illustrate the structural "plasticity" of the polymer and the adaptability of the lignification mechanisms in plants (Boerjan et al., 2003; Ralph, 2007). However, several of these compounds (such as $p$-hydroxycinnamaldehydes, ferulic acid or 5-hydroxyconiferyl alcohol) only provide a significant contribution to lignin in transgenic plants with modified monolignol biosynthesis (Ralph, 2007; Vanholme et al., 2008) and are minor lignin precursors in normal plants (del Río et al., 2007c). On the other hand, some phenolic compounds with saturated or no side-chains, e.g. dihydrocinnamyl alcohol, sporadically 


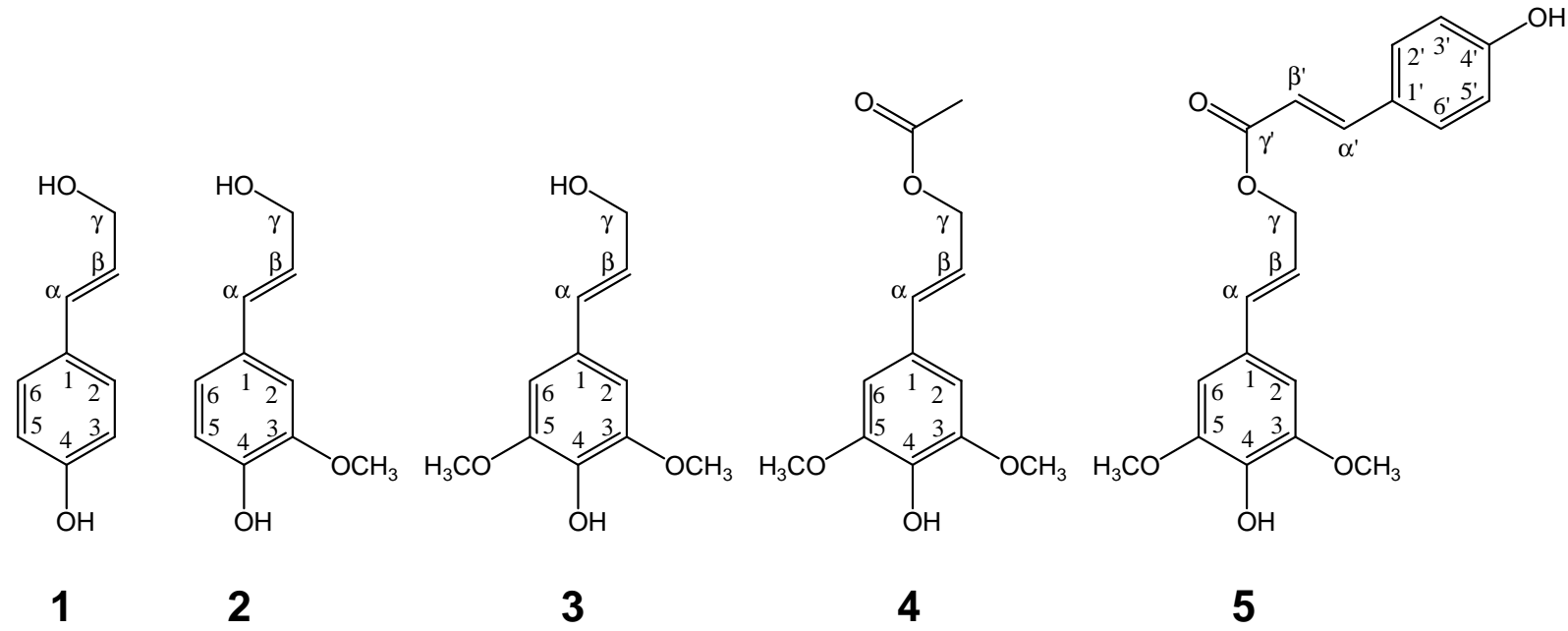

Fig. 1. Classical and acylated monolignols acting as precursors of nonwoody lignins: (1) p-coumaryl alcohol; (2) coniferyl alcohol; (3) sinapyl alcohol; (4) sinapyl acetate; and (5) sinapyl $p$-coumarate.

incorporate to the lignin polymer as terminal units as confirmed by 2D NMR (Balakshin et al., 2005; Zhang et al., 2003).

A significant exception to the only sporadic contribution of "non-classic" monolignols has been found in several plants that seem to use acylated monolignols to synthesize highly-acylated lignins. Lignin from kenaf (Hibiscus cannabinus L.) bast fibers was one of the first examples including up to $60 \%$ acetylated S units (Ralph, 1996) derived from sinapyl acetate (Lu and Ralph, 2002) (Fig. 1, structure 4). After a preliminary study using analytical pyrolysis (del Río et al., 2004), we recently showed by modified DFRC (derivatization followed by reductive cleavage) that lignin acetylation is widespread among nonwoody angiosperms (del Río et al., 2007b) with some lignins showing even higher extent of acetylation (up to $80 \%$ of S units) than kenaf lignin. Surprisingly, different degrees of lignin acetylation were also found in all the woody angiosperms analyzed, attaining up to $45 \%$ acetylation of $\mathrm{S}$ units in Carpinus betulus L. lignin, although it seemed to be absent from gymnosperm lignins. Acetic acid is not the only organic acid esterifying monolignols. Maize (Zea mays L.) lignin is p-coumaroylated, again predominantly at the S units (Lu and Ralph, 1999; Ralph et al., 1994) that would derive from sinapyl $p$-coumarate (Fig. 1, structure 5), and the same has been suggested for Musa textilis Nee (abaca) lignin (del Río et al., 2007b). Moreover, $p$-hydroxybenzoylation has been reported in lignins from different origins (Landucci et al., 1992; Smith, 1955b; Sun et al., 1999).

The presence of acylating groups in some lignins is known for long time (Smith, 1955a), although only recently it has been shown that lignin acylation is widespread among angiosperms, and recognized that the esterification reaction occurred at the monolignol level (Lu and Ralph, 2002; Lu et al., 2004). However, little is known about the structural or functional role of the lignin acylation processes. The difficulties for recognizing the influence of monolignol acylation on lignin structure are related to the complexity of the lignin polymer and the difficulties for its accurate structural analysis, which are being overcome by the use of modern analytical techniques. Development of 2D (and 3D) NMR provided a powerful tool for lignin analysis, since signals overlapping in the ${ }^{1} \mathrm{H}$ and ${ }^{13} \mathrm{C}$ NMR spectra were resolved revealing both the aromatic units and the different inter-unit linkages present in lignin (Ralph et al., 1999). Signals related to the already known inter-unit linkages were already identified in the first 2D NMR spectra of lignins (Ede and Brunow, 1992; Fukagawa et al., 1991). Moreover, this technique enabled the discovery of dibenzodioxocins (Karhunen et al., 1995) and spirodienones (Zhang and Gellerstedt, 2001) as two new lignin sub- structures. 2D NMR has been successfully applied to the structural characterization of lignins in wood and their modification in paper pulp manufacturing (Balakshin et al., 2001, 2003; Capanema et al., 2001; Chen et al., 2003; Ibarra et al., 2007a,b). However, studies on nonwoody lignins are comparatively scarce (Crestini and Argyropoulos, 1997; Galkin et al., 1997; Ralph et al., 1994; Sun et al., 2005). In the present paper, lignin preparations from three nonwoody angiosperms - Agave sisalana Perrine (sisal), M. textilis, and Cannabis sativa L., (hemp) were characterized by heteronuclear single quantum correlation (HSQC) 2D NMR. The results obtained suggested a possible role of monolignol acylation regulating the structure of lignin in angiosperm plants.

\section{Results and discussion}

\subsection{Lignins analyzed}

2D NMR was used to investigate lignin structure and acylation type and degree in three selected nonwoody angiosperms. Three lignin preparations were analyzed by NMR for each of the plant species investigated: milled-wood-lignin (MWL), in vitro acetylated MWL, and alkalilignin. MWL (Björkman, 1956) is often considered as the election preparation in lignin studies, in spite of its low yield and the existence of some modification during milling (Holtman et al., 2006). Moreover, lignin S/G ratio and acylation degree, similar to those described below after MWL isolation, have been found by 2D NMR of the whole plant material at the gel state (Rencoret et al., 2008b). Most NMR studies of lignins were carried out in acetylated samples to increase their solubility (Ralph et al., 1999). However, this prevented detection of natural acetylation, and explains why the widespread occurrence of acetylation in angiosperm lignins reported by del Río et al. (2007b) was not described earlier. In the present study, the HSQC spectra of lignins were acquired from both underivatized and in vitro acetylated MWL samples. The former revealed the natural acylation of lignin, whereas the latter informed on free hydroxyl groups and contributed to cross-signal assignment by comparison with the literature. Finally, alkalilignin samples obtained from plant fibers informed on the presence of alkali-labile bonds in lignins. The main crosssignals identified in the different regions of the HSQC spectra are discussed below, followed by a description of the different lignins analyzed, and a discussion on the possible influence of acylation on lignin structure and biosynthesis. 


\subsection{Whole HSQC NMR spectra}

Figs. 2-4 present the most informative region of the HSQC spectra of MWL (a), acetylated MWL (b) and alkalilignin (c) from $A$. sisalana, $M$. textilis and $C$. sativa, respectively. The main classical and naturally-acylated substructures identified are depicted in Fig. 5. The HSQC spectra show the aromatic/olefinic ${ }^{1} \mathrm{H}-{ }^{13} \mathrm{C}$ correlations $\left(\delta_{\mathrm{H}} / \delta_{\mathrm{C}} 5.5-7.5 / 100-135 \mathrm{ppm}\right.$ region $)$ and the aliphatic-oxygenated ${ }^{1} \mathrm{H}-{ }^{13} \mathrm{C}$ correlations $\left(\delta_{\mathrm{H}} / \delta_{\mathrm{C}} \quad 2.5-6.5 / 50-90 \mathrm{ppm}\right.$ region) informing on lignin aromatic units and side-chain inter-unit linkages, respectively. The $\beta-\beta^{\prime}$ structures (B and $\mathbf{B}^{\prime}$ ) and phenylcoumaran (C) non-oxygenated $\mathrm{H}_{\beta}-\mathrm{C}_{\beta}$ correlation signals are shown together with the aliphatic-oxygenated signals because of similar chemical shifts. Some carbohydrate signals were also found with $\delta_{\mathrm{H}} / \delta_{\mathrm{C}} 2.7-3.9 / 62-82 \mathrm{ppm}$, and 4-5/100-105 ppm for the anomeric signal.

The aliphatic non-oxygenated region of the spectra $\left(\delta_{\mathrm{H}} / \delta_{\mathrm{C}} 0-\right.$ $4.5 / 0-50 \mathrm{ppm}$ ) is not shown because most signals were unidentified or scarcely informative, excepting those of the acetate methyls that were used to estimate the phenolic and alcoholic hydroxyls in MWL after in vitro acetylation (signals with $\delta_{\mathrm{H}} / \delta_{\mathrm{C}}$ around 2.2-2.3/ $21 \mathrm{ppm}$ and 1.8-2.1/21 ppm, respectively) and the degree of natural acetylation of MWL (from the $\delta_{\mathrm{H}} / \delta_{\mathrm{C}} 1.7-2.0 / 21 \mathrm{ppm}$ correlation). This information, as well as the total integrals of the above aromatic, alyphatic oxygenated and non-oxygenated regions (the latter after deducing the dimethylsulfoxide (DMSO), signal) are included in Table 1 (these raw integrals are not corrected taking into account the number of hydrogens per carbon). On the other hand, no significant signals with $\delta_{\mathrm{C}} 147-205 \mathrm{ppm}$ were found.

\subsection{Lignin side-chain region of the HSQC spectra}

Cross-signals of methoxyl substituents $\left(\delta_{\mathrm{H}} / \delta_{\mathrm{C}} 3.72 / 56.2 \mathrm{ppm}\right)$ and ring side-chains in classical (non-acylated) and acylated lignin substructures were found in the aliphatic-oxygenated region of the spectra.

The main signals corresponded to classical $\beta-O-4^{\prime}(\mathbf{A}) \mathrm{H}_{\alpha}-\mathrm{C}_{\alpha}\left(\delta_{\mathrm{H}} /\right.$ $\left.\delta_{\mathrm{C}} 4.73-4.86 / 71.7-72.3 \mathrm{ppm}\right)$ and $\mathrm{H}_{\beta}-\mathrm{C}_{\beta}\left(\delta_{\mathrm{H}} / \delta_{\mathrm{C}} 4.01-4.28 / 84.3-\right.$ $87.1 \mathrm{ppm})$ correlations, and resinol (B) $\mathrm{H}_{\alpha}-\mathrm{C}_{\alpha}\left(\delta_{\mathrm{H}} / \delta_{\mathrm{C}} 4.65 /\right.$ $85.6 \mathrm{ppm}), \mathrm{H}_{\beta}-\mathrm{C}_{\beta}\left(\delta_{\mathrm{H}} / \delta_{\mathrm{C}} 3.05 / 54.1 \mathrm{ppm}\right)$ and double $\mathrm{H}_{\gamma}-\mathrm{C}_{\gamma}\left(\delta_{\mathrm{H}} / \delta_{\mathrm{C}}\right.$ $3.82 / 71.6$ and $4.18 / 71.6 \mathrm{ppm}$ ) correlations. These signals appeared together with naturally $\gamma$-acylated $\beta-O-4^{\prime}\left(\mathbf{A}^{\prime}\right) \mathrm{H}_{\alpha}-\mathrm{C}_{\alpha}\left(\delta_{\mathrm{H}} / \delta_{\mathrm{C}} 4.85-\right.$ 4.96/72.2-72.8 ppm, overlapping with same signal in $(\mathbf{A})$ and $\mathrm{H}_{\beta}-$ $\mathrm{C}_{\beta}\left(\delta_{\mathrm{H}} / \delta_{\mathrm{C}} 4.32 / 83.6 \mathrm{ppm}\right)$ correlation signals.

Signals of phenylcoumaran (C) $\mathrm{H}_{\alpha}-\mathrm{C}_{\alpha}\left(\delta_{\mathrm{H}} / \delta_{\mathrm{C}} 5.45 / 87.5 \mathrm{ppm}\right)$ and $\mathrm{H}_{\beta}-\mathrm{C}_{\beta}\left(\delta_{\mathrm{H}} / \delta_{\mathrm{C}} 3.42 / 53.7 \mathrm{ppm}\right)$ and spirodienone (D) $\mathrm{H}_{\alpha}-\mathrm{C}_{\alpha}$ $\left(\delta_{\mathrm{H}} / \delta_{\mathrm{C}} 5.12 / 82.1 \mathrm{ppm}\right), \mathrm{H}_{\alpha^{\prime}}-\mathrm{C}_{\alpha^{\prime}}\left(\delta_{\mathrm{H}} / \delta_{\mathrm{C}} 4.80 / 85.5 \mathrm{ppm}\right), \mathrm{H}_{\beta}-\mathrm{C}_{\beta}\left(\delta_{\mathrm{H}} /\right.$ $\left.\delta_{\mathrm{C}} 3.10 / 56.4 \mathrm{ppm}\right)$ and $\mathrm{H}_{\beta^{\prime}}-\mathrm{C}_{\beta^{\prime}}\left(\delta_{\mathrm{H}} / \delta_{\mathrm{C}} 4.31 / 76.4 \mathrm{ppm}\right)$ correlations were also detected, although with much lower intensities (the latter is not labeled on the spectra).

Minor $\mathrm{H}_{\alpha}-\mathrm{C}_{\alpha}\left(\delta_{\mathrm{H}} / \delta_{\mathrm{C}} 4.97 / 83.4\right)$ and $\mathrm{H}_{\beta}-\mathrm{C}_{\beta}\left(\delta_{\mathrm{H}} / \delta_{\mathrm{C}} 2.47 / 50.1 \mathrm{ppm}\right)$ correlation signals of diacylated $\beta-\beta^{\prime}$ dimeric structures $\left(\mathbf{B}^{\prime}\right)$ were detected. Their identification was based on previous HSQC and HSQC-TOCSY studies of in vitro (Zhang and Gellerstedt, 2004) and naturally-acetylated lignins (Lu and Ralph, 2005). The neighbor signal $\left(\delta_{\mathrm{H}} / \delta_{\mathrm{C}} 2.32 / 53.5 \mathrm{ppm}\right)$ was not assigned, but it does not correspond to the non-acylated form of the unusual $\beta-\beta^{\prime}$ structures since it is not displaced after in vitro acetylation. $\mathrm{H}_{\gamma}-\mathrm{C}_{\gamma}$ correlation signals in minor phenylcoumaran substructures $\left(\delta_{\mathrm{H}} / \delta_{\mathrm{C}} 3.8 / 63 \mathrm{ppm}\right)$ overlapped with other cross-signals and, therefore, their natural acylation could not be separately evaluated.

In the in vitro acetylated lignins (Figs. $2 \mathrm{~b}, 3 \mathrm{~b}$ and $4 \mathrm{~b}) \alpha, \gamma$-diacetylated $\beta-0-4^{\prime}\left(\mathbf{A}^{\prime \prime}\right) \mathrm{H}_{\alpha}-\mathrm{C}_{\alpha}\left(\delta_{\mathrm{H}} / \delta_{\mathrm{C}} 5.92 / 74.5 \mathrm{ppm}\right)$ and $\mathrm{H}_{\beta}-\mathrm{C}_{\beta}\left(\delta_{\mathrm{H}} / \delta_{\mathrm{C}}\right.$ $4.58 / 80.7 \mathrm{ppm}$ ) correlations were found, the former being strongly displaced with respect to the classical and naturally $\gamma$-acylated substructures. However, the broad $\mathrm{H}_{\gamma}-\mathrm{C}_{\gamma}$ correlation signal was scarcely displaced with respect to the cross-signal of the monoacylated substructure.

\subsection{Aromatic/olefinic region of the HSQC spectra}

The main cross-signals in the unsaturated region of the spectra corresponded to the lignin aromatic rings, and the aromatic ring and olefinic side-chain of $p$-coumaric acid.

In $S$ units only $C_{2}$ and $C_{6}$ are protonated resulting in a unique and large $\mathrm{H}_{2,6}-\mathrm{C}_{2,6}$ correlation $\left(\delta_{\mathrm{H}} / \delta_{\mathrm{C}} 6.67 / 104.0 \mathrm{ppm}\right)$ signal. By contrast, three different cross-signals were assigned to $(\mathbf{G}) \mathrm{H}_{2}-\mathrm{C}_{2}$ $\left(\delta_{\mathrm{H}} / \delta_{\mathrm{C}} \quad 6.98 / 111.6 \mathrm{ppm}\right), \quad \mathrm{H}_{5}-\mathrm{C}_{5} \quad\left(\delta_{\mathrm{H}} / \delta_{\mathrm{C}} \quad 6.69 / 115.2\right.$ and $6.94 /$ $115.7 \mathrm{ppm})$ and $\mathrm{H}_{6}-\mathrm{C}_{6}\left(\delta_{\mathrm{H}} / \delta_{\mathrm{C}} 6.77 / 119.6 \mathrm{ppm}\right)$ correlations. Two signals were assigned to $\mathrm{H}_{3,5}-\mathrm{C}_{3,5}\left(\delta_{\mathrm{H}} / \delta_{\mathrm{C}} 6.63 / 115.4 \mathrm{ppm}\right)$ and $\mathrm{H}_{2,6}-\mathrm{C}_{2,6}\left(\delta_{\mathrm{H}} / \delta_{\mathrm{C}} 7.03 / 130.5 \mathrm{ppm}\right)$ correlations in $(\mathbf{H})$, the former overlapping with the $\mathrm{H}_{5}-\mathrm{C}_{5}$ correlation signal in $\mathrm{G}$ units. Signals of $\mathrm{H}_{2,6}-\mathrm{C}_{2,6}$ correlation $\left(\delta_{\mathrm{H}} / \delta_{\mathrm{C}} \quad 7.22-7.36 / 106.8-107.0 \mathrm{ppm}\right)$ in $\mathrm{C}_{\alpha--} \mathrm{O} \mathrm{S}$ units $\left(\mathbf{S}^{\prime}\right)$ were found in all lignins. The nature of these units has been reported by HMBC NMR (Ibarra et al., 2007a,b). Minor signals of spirodienone (D) $\mathrm{H}_{2^{\prime}}-\mathrm{C}_{2^{\prime}}\left(\delta_{\mathrm{H}} / \delta_{\mathrm{C}} 6.23 / 111.6 \mathrm{ppm}\right)$ and $\mathrm{H}_{6^{\prime}}-\mathrm{C}_{6^{\prime}}\left(\delta_{\mathrm{H}} / \delta_{\mathrm{C}} 6.19 / 118.3 \mathrm{ppm}\right)$ correlations were also found.

The $p$-coumaric acid (E) signals corresponded to aromatic $\mathrm{H}_{2,6}-$ $\mathrm{C}_{2,6}\left(\delta_{\mathrm{H}} / \delta_{\mathrm{C}} 7.44 / 130.6 \mathrm{ppm}\right)$ and $\mathrm{H}_{3,5}-\mathrm{C}_{3,5}\left(\delta_{\mathrm{H}} / \delta_{\mathrm{C}} 6.77 / 116.2 \mathrm{ppm}\right)$ and olefinic $\mathrm{H}_{\alpha}-\mathrm{C}_{\alpha}\left(\delta_{\mathrm{H}} / \delta_{\mathrm{C}} 7.39 / 145.1 \mathrm{ppm}\right)$ and $\mathrm{H}_{\beta}-\mathrm{C}_{\beta}\left(\delta_{\mathrm{H}} / \delta_{\mathrm{C}}\right.$ $6.11-6.24 / 114.3 \mathrm{ppm}$ ) correlations.

The $p$-coumaric acid $\mathrm{H}_{3,5}-\mathrm{C}_{3,5}$ correlation signal was strongly displaced after in vitro acetylation $\left(\delta_{\mathrm{H}} / \delta_{\mathrm{C}} 7.15 / 122.8 \mathrm{ppm}\right)$ indicating that the acid maintained the free phenolic hydroxyl. In vitro acetylation also caused significant displacement of some G-unit $\mathrm{H}_{5}-\mathrm{C}_{5}$ and $\mathrm{H}$-unit $\mathrm{H}_{3,5}-\mathrm{C}_{3,5}$ correlation signals revealing phenolic structures. In both cases, as well as in $\mathrm{S}$ units, $\mathrm{H}_{2}-\mathrm{C}_{2}$ and $\mathrm{H}_{6}-\mathrm{C}_{6}$ cross-signals were scarcely modified due to the higher distance to free hydroxyls. On the other hand, the alkaline treatment resulted in broadening of the aromatic signals, which was especially evident for the $S$ units, as well as in the lost of $p$-coumarate aromatic and olefinic signals, and acetate methyl signals.

\subsection{Characteristics of the A. sisalana lignin}

The HSQC spectra of the A. sisalana lignins (MWL, acetylated MWL and alkalilignin) are shown in Fig. 2, and a summary of the main inter-unit linkages, H:G:S ratio, acylation degree, phenolic content (after in vitro acetylation) and other characteristics are shown in Table 1.

The aromatic region of the spectra revealed a strong predominance of S units (MWL H:G:S ratio 0:20:80) in agreement with previous studies (del Río et al., 2004, 2007b). The MWL S/G ratio from NMR spectra was higher than estimated from DFRC, but similar to that obtained from analytical pyrolysis of the whole fiber. Integration of phenolic acetate signals showed $11 \%$ phenolic units in the $A$. sisalana MWL, which represented the lowest phenolic content amongst the three nonwoody lignins.

The side-chain region of the MWL spectra showed a strong frequency (near $90 \%$ of side-chains) of $\beta-O-4^{\prime}$ substructures (Table 1 ). Some spirodienones were present (which were also identifiable in the aromatic/olefinic region) together with small amounts of $\beta-\beta^{\prime}$ and phenylcoumaran structures. More interesting, the spectrum revealed that most of the $\beta-O-4^{\prime}$ substructures in the $A$. sisalana MWL were acylated at the $\gamma$-position, as shown by the characteristic displacements (see Section 2.3) and intensities of the $\mathbf{A}_{\beta}^{\prime}$ and $\mathbf{A}_{\gamma}^{\prime}$ cross-signals. The absence of $p$-coumarate signals and the high intensity of the acetate methyl signal, showed that acetates are the only acylating groups, in agreement with DFRC results (del Río et al., 2007b). Interestingly, a small percentage of $\beta-0-4^{\prime}$ sidechains (around 5\%) were $\alpha$-acetylated with a characteristic $\mathrm{H}_{\alpha^{-}}$ $\mathrm{C}_{\alpha}$ correlation, similar to that found after in vitro peracetylation. 


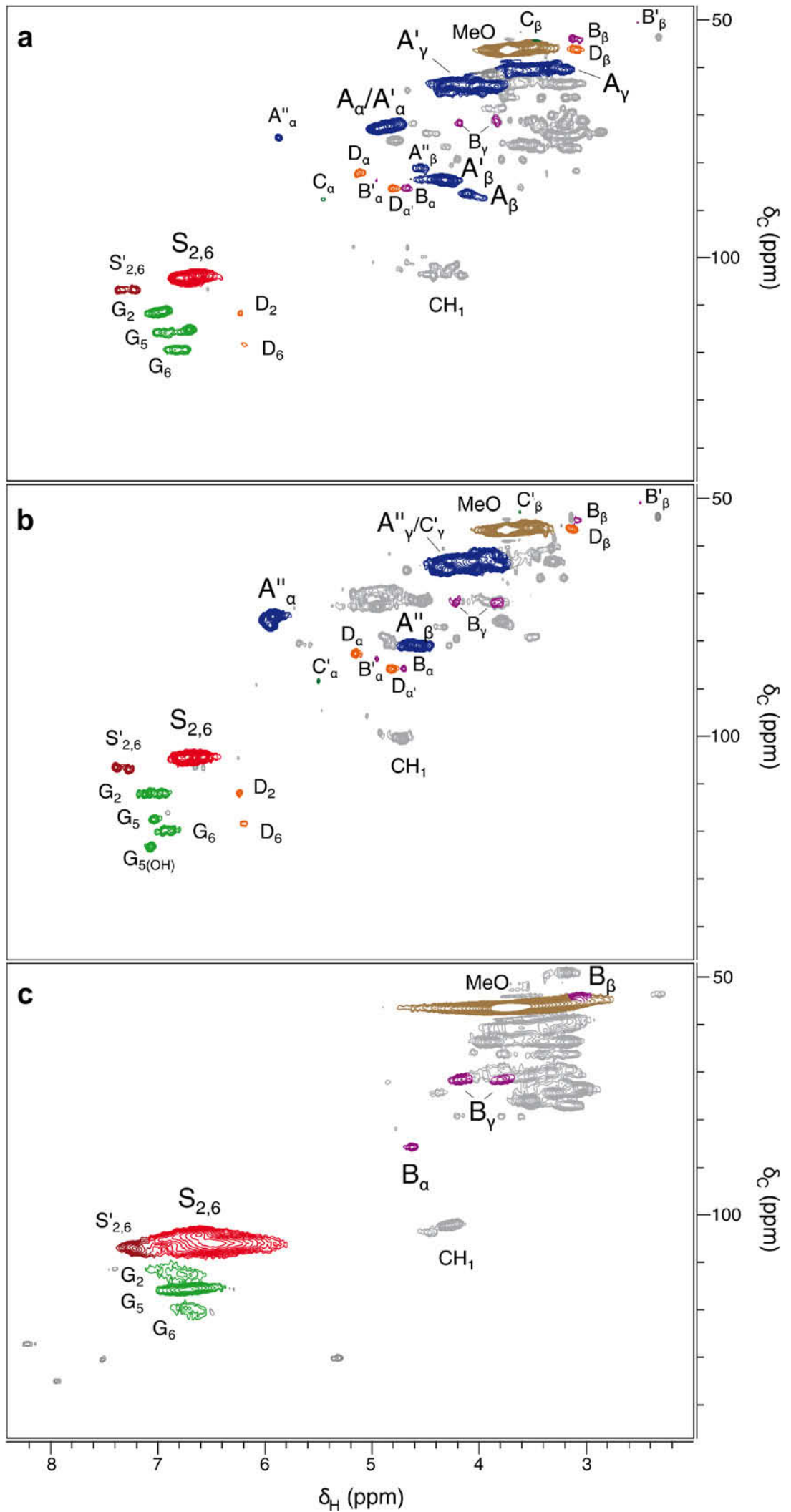

Fig. 2. Expanded HSQC spectra, $\delta_{\mathrm{H}} / \delta_{\mathrm{C}} 2.0-8.4 / 47-147 \mathrm{ppm}$, of $A$. sisalana MWL (a), in vitro acetylated MWL (b) and alkalilignin (c) showing the main side-chain and aromatic ${ }^{1} \mathrm{H}-{ }^{13} \mathrm{C}$ correlation signals. See Fig. 5 for the main lignin structures identified (some carbohydrate signals were also obtained including those of $\mathrm{CH}_{1}$; $\mathrm{G}_{5(\mathrm{OH})}$ signals correspond to phenolic units that were in vitro acetylated).

Since monolignol acylation is only possible at the $\gamma$-position, acetate migration has been suggested (Ralph, 1996). Diacylated $\beta-\beta^{\prime}$ dimeric structures $\left(\mathbf{B}^{\prime}\right)$ were found, together with the typical resi- nol structures (B), although with very low abundance (Table 1). The presence of diacetylated tetrahydrofuran $\beta-\beta^{\prime}$ structures in this lignin had been revealed by modified DFRC (del Río et al., 


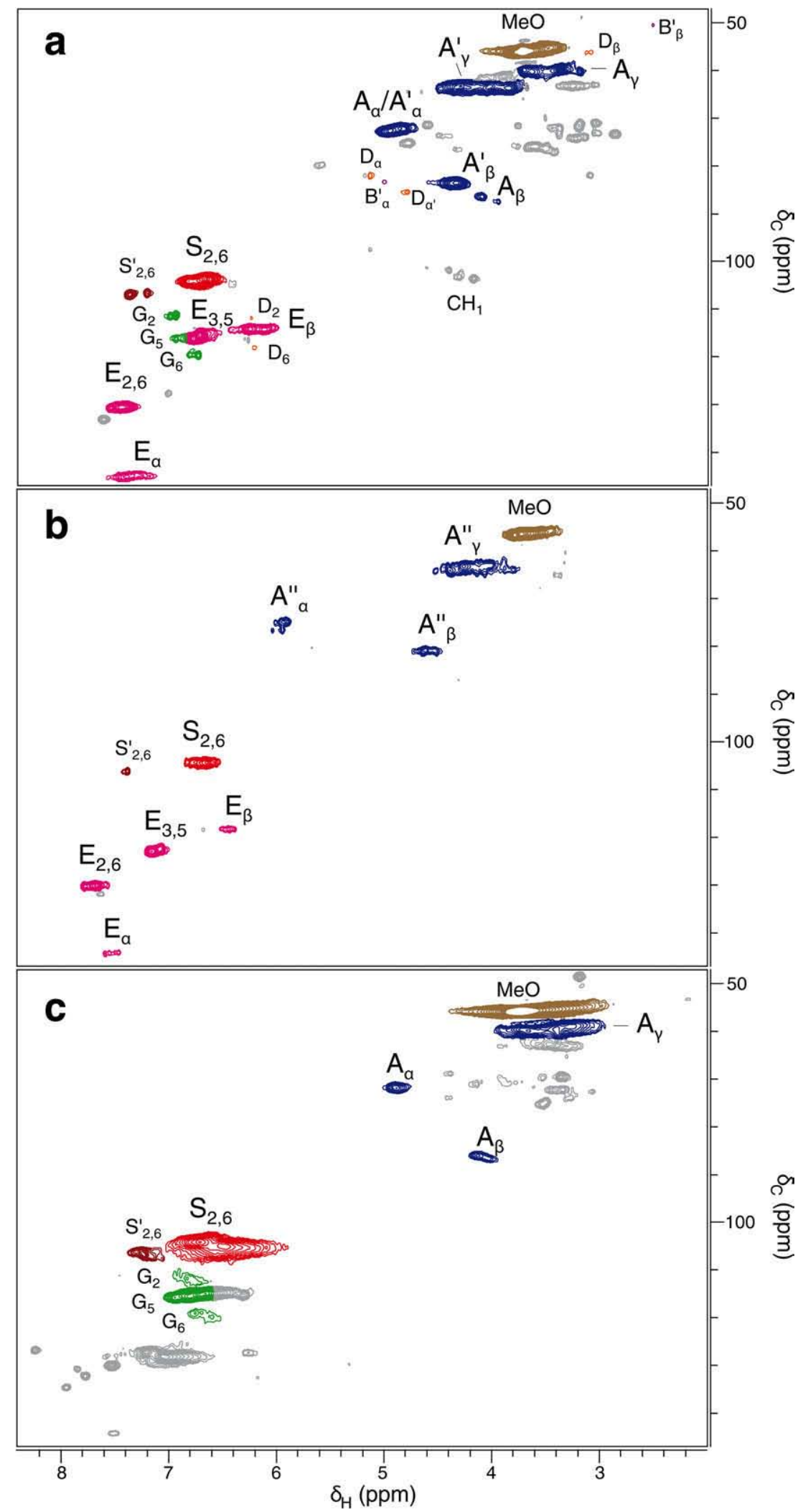

Fig. 3. Expanded HSQC spectra, $\delta_{\mathrm{H}} / \delta_{\mathrm{C}} 2.0-8.4 / 47-147 \mathrm{ppm}$, of $M$. textilis $\mathrm{MWL}$ (a), in vitro acetylated MWL (b) and alkalilignin (c) showing the main side-chain and aromatic/ olefinic ${ }^{1} \mathrm{H}-{ }^{13} \mathrm{C}$ correlation signals. See Fig. 5 for the main lignin structures identified (some carbohydrate signals were also obtained including those of anomeric ${ }^{1} \mathrm{H}-{ }^{13} \mathrm{C}$ correlations, $\mathrm{CH}_{1}$ ).

2007b). DFRC also showed the presence of monoacetylated $\beta-\beta^{\prime}$ structures, whereas only the diacylated ones were detected by
NMR, in agreement with their higher abundance in lignins with similar acylation degrees (Lu and Ralph, 2005). 


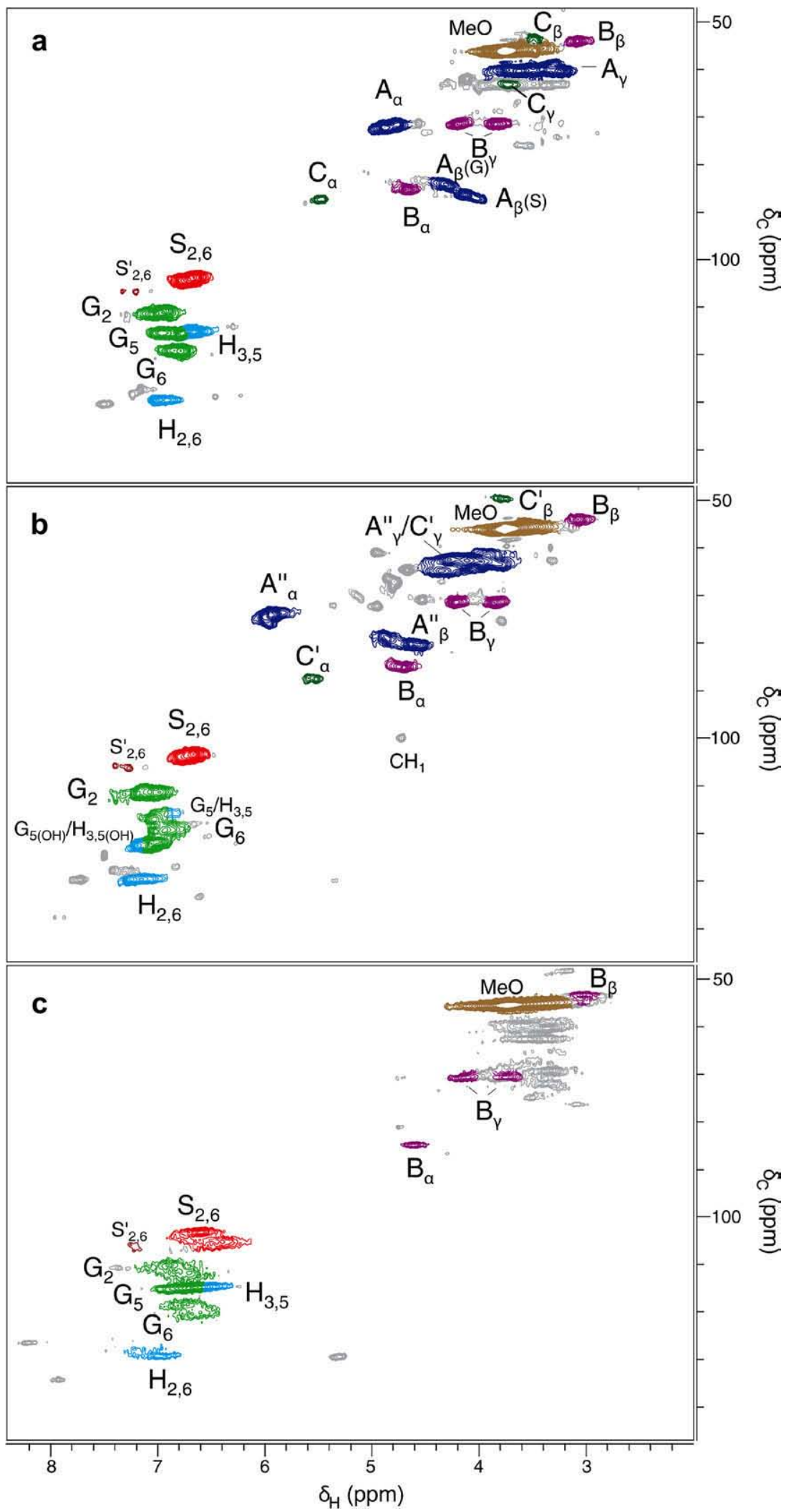

Fig. 4. Expanded HSQC spectra, $\delta_{\mathrm{H}} / \delta_{\mathrm{C}} 2.0-8.4 / 47-147 \mathrm{ppm}$, of $C$. sativa MWL (a), in vitro acetylated MWL (b) and alkalilignin (c) showing the main side-chain and aromatic ${ }^{1} \mathrm{H}-{ }^{13} \mathrm{C}$ correlation signals. See Fig. 5 for the main lignin structures identified (some carbohydrate signals were also obtained including those of $\mathrm{CH}_{1}$; $\mathrm{G}_{5(\mathrm{OH})}$ and $\mathrm{H}_{3,5(\mathrm{OH})}$ signals correspond to phenolic units that were in vitro acetylated).

Alkali treatment of the $A$. sisalana fibers destroyed a part of the $\beta-0-4^{\prime}$ linkages resulting in an alkalilignin enriched in $\beta-\beta^{\prime}$ substructures. In contrast to that observed with the other lignins, the $S / G$ ratio increased. Some lignin-carbohydrate linkages in $A$. sisalana resisted the alkali treatment, whereas carbohydrates were practically absent from the two other alkalilignins. 


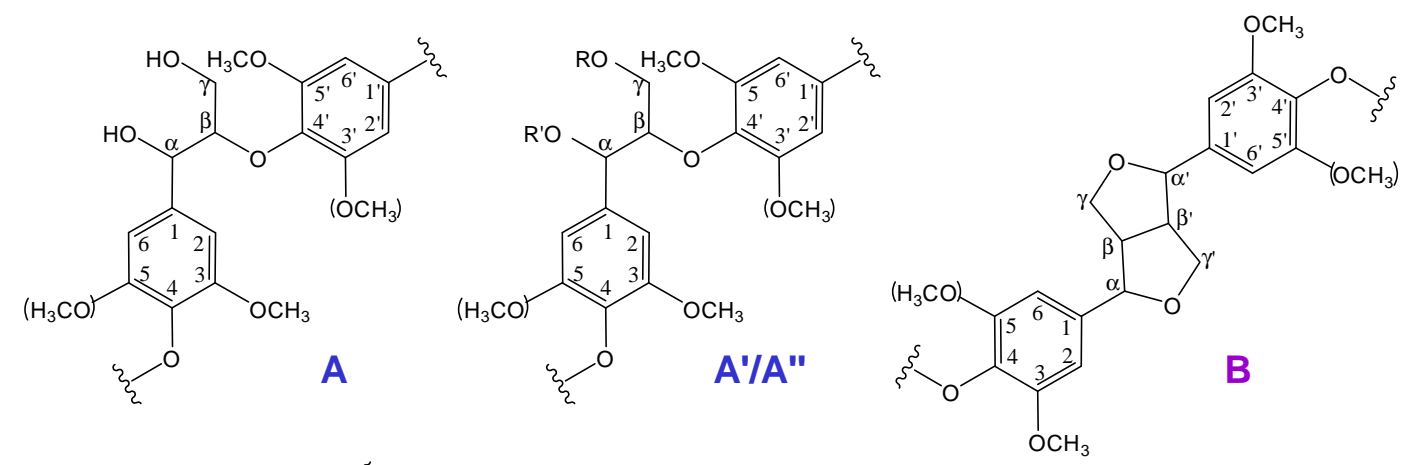

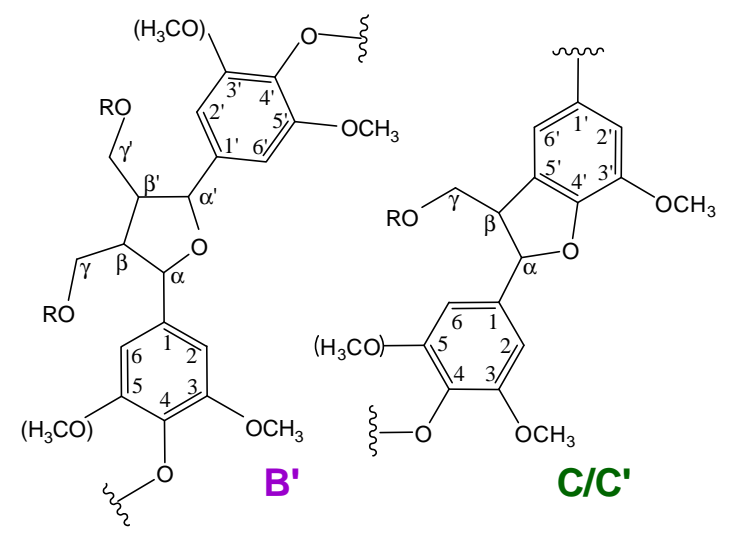<smiles>[Y]C(O)[C@H](O)[C@H]1O[C@@H](c2cc(OC)c(OCC)c(OC)c2)[C@]2(C=C(O)C(=O)[C@@H](OC)C2)[C@@H]1CO</smiles><smiles>CCOC(O)C=Cc1ccc(O)cc1</smiles>

E<smiles>CCOc1ccc(C(C)O)cc1</smiles><smiles>CCOc1ccc(C(C)O)cc1OC</smiles><smiles>COc1cc(C(C)O)cc(OC)c1OC</smiles><smiles>COc1cc(C(C)=O)cc(OC)c1OCC(=O)O</smiles>

Fig. 5. Main classical and acylated substructures, involving different side-chain linkages, and aromatic units identified by $2 \mathrm{D}$ NMR of the $A$. sisalana, $M$. textilis and $C$. sativa lignins: (A) $\beta-0$-4' substructure; $\left(\mathbf{A}^{\prime}\right) \gamma$-acylated $\beta$ - $O-4^{\prime}$ substructure $\left(R\right.$, acetyl $/ p$-coumaroyl; $\left.R^{\prime}, \mathrm{H}\right) ;\left(\mathbf{A}^{\prime \prime}\right) \alpha$-acylated $\beta$ - $O$ - $4^{\prime}$ substructure, being especially abundant in the in vitro acetylated lignins where it is diacylated $\left(R\right.$, acetyl $/ p$-coumaroyl; and $R^{\prime}$, acetyl); (B) resinol substructure, formed by $\beta-\beta^{\prime}$ coupling and $\alpha$ - $O$ - $\gamma^{\prime}$ and $\gamma$ - $O$ - $\alpha^{\prime}$ bonding during quinone methide rearomatization; ( $\left.\mathbf{B}^{\prime}\right)$ di- $\gamma$-acylated mono-tetrahydrofuran structure formed by $\beta$ - $\beta^{\prime}$ coupling and subsequent $\alpha$ - $O$ - $\alpha^{\prime}$ bonding $(R$, acetyl $/ p$-coumaroyl); (C) phenylcoumaran, formed by $\beta-5^{\prime}$ coupling and subsequent $\alpha-O-4^{\prime}$ bonding $(R, \mathrm{H}) ;\left(\mathbf{C}^{\prime}\right) \gamma$-acetylated phenylcoumaran $\left(R\right.$, acetyl); (D) Spirodienone, formed by $\beta-1^{\prime}$ coupling and subsequent $\alpha-O-\alpha^{\prime}$ bonding; $(\mathbf{H})$ p-hydroxyphenyl unit; $(\mathbf{G})$ guaiacyl unit; $(\mathbf{S})$ syringyl unit; and $\left(\mathbf{S}^{\prime}\right)$ oxidized syringyl units with a $C_{\alpha}$ ketone or a $C_{\alpha}$ carboxyl group. A-D correspond to non-acylated substructures; $\mathbf{A}^{\prime}$ and $\mathbf{B}^{\prime}$ correspond to naturally-acylated substructures; and $\mathbf{A}^{\prime \prime}$ and $\mathbf{C}^{\prime}$ basically correspond to in vitro acetylated substructures. No specific signals corresponding to acylated $\mathbf{D}$ could be detected (even after in vitro acetylation). Only main substructures (with a relative abundance $>1 \%$ of total sidechains) are presented.

\subsection{Characteristics of the M. textilis lignin}

The HSQC spectra of the M. textilis lignins are shown in Fig. 3, and their main characteristics are described in Table 1. The aromatic region of the spectrum showed an S-rich lignin (H:G:S ratio of $0: 10: 90$ ) with $S / G$ ratio even higher than reported by analytical pyrolysis of the whole fiber (del Río and Gutiérrez, 2006) and DFRC of the isolated MWL (del Río et al., 2007b). This is an exceptionally S-rich lignin, although higher S content (95\% S units) has been recently described in Rheum rhabarbarum L. (rhubarb) lignin (Bunzel and Ralph, 2006).

Presence of $p$-coumaric acid (E) was revealed by its characteristic cross-signals $\left(E_{\alpha}, E_{\beta}\right.$ and $\left.E_{2,6}\right)$ that could be observed in both the MWL and in vitro acetylated MWL spectra. The strong displacement of the $E_{3,5}$ cross-signal after in vitro acetylation indicated that the $p$-coumaric acid was ester-linked with lignin (at the side-chain $\gamma$-position, as discussed above). In vitro acetylation showed the highest content of phenolic structures in this MWL estimated from the phenolic acetate cross-signals (Table 1). Most of these free phenolic groups probably corresponded to the $p$-coumaroyl substituents, and the real percentage of phenolic $G$ and $S$ lignin units was probably around $10 \%$, as found in the A. sisalana MWL.

The side-chain region of the MWL spectrum showed the absence of $\beta-\beta^{\prime}$ resinols and a strong predominance of $\beta-O-4^{\prime}$ substructures, accompanied by some spirodienones (Table 1 ). It also revealed that most of the $\beta-O-4^{\prime}$ substructures in the $M$. textilis MWL were acylated at the $\gamma$-position $\left(\mathbf{A}^{\prime}\right)$, the acylation degree (around 85\%) being even higher than reported for other lignins analyzed up to date. It had been reported that the $M$. textilis MWL was extensively acetylated but also presented some $p$-coumaroylation (del Río et al., 2007a,b; del Río and Gutiérrez, 2006). This agreed with the HSQC information indicating that around 
Table 1

Inter-unit linkages (\% of side-chains involved in substructures A-D), H, G and S contents, S/G ratio, acylation degree (\% of $\beta-0-4^{\prime}$ substructures), $p$-coumarate content (\% of $\mathrm{H}+\mathrm{G}+\mathrm{S}$ ), phenolic content (\% of $\mathrm{H}+\mathrm{G}+\mathrm{S}$, after MWL acetylation), phenolic-to-alcoholic hydroxyl ratio (after MWL acetylation), carbohydrate content ( $\mathrm{CH} \mathrm{H}_{1}$ as \% of $\mathrm{H}+\mathrm{G}+\mathrm{S}$ ), and integrals of the aliphatic non-oxygenated, aliphatic oxygenated and aromatic regions (\% of total integration) of MWL, and alkalilignin from A. sisalana, M. textilis and C. sativa as revealed by HSQC 2D NMR (cross-signal integration as described in the Section 4)

\begin{tabular}{|c|c|c|c|c|c|c|}
\hline & \multicolumn{2}{|c|}{ A. sisalana } & \multicolumn{2}{|c|}{ M. textilis } & \multicolumn{2}{|c|}{ C. sativa } \\
\hline & MWL & Alkalilignin & MWL & Alkalilignin & MWL & Alkalilignin \\
\hline$\beta-O-4^{\prime}(\mathrm{A})$ & 87 & 33 & 93 & 100 & 69 & 16 \\
\hline$\beta-\beta^{\prime}$ Resinols (B) & 4 & 67 & 0 & 0 & 22 & 84 \\
\hline Acylated $\beta-\beta^{\prime}\left(\mathbf{B}^{\prime}\right)$ & 2 & 0 & 2 & 0 & 0 & 0 \\
\hline Phenylcoumaran (C) & 2 & 0 & 0 & 0 & 9 & 0 \\
\hline Spirodienone (D) & 5 & 0 & 5 & 0 & 0 & 0 \\
\hline$\beta-\beta^{\prime} / \beta-O-4^{\prime}\left(\left(\mathbf{B}+\mathbf{B}^{\prime}\right) / \mathbf{A}\right)$ & 0.07 & 2.00 & 0.02 & 0 & 0.32 & 5.26 \\
\hline $\mathrm{H}(\%)$ & 0 & 0 & 0 & nd & 12 & 13 \\
\hline$G(\%)$ & 20 & 16 & 10 & 14 & 49 & 66 \\
\hline $\mathrm{S}(\%)$ & 80 & 84 & 90 & 86 & 39 & 21 \\
\hline S/G ratio & 3.9 & 5.3 & 8.8 & 6.4 & 0.8 & 0.3 \\
\hline Acylation degree & $79^{\circ}$ & 0 & 84 & 0 & 0 & 0 \\
\hline$p$-Coumarate content & 0 & 0 & 40 & 1 & 0 & 0 \\
\hline p-Coumarate/acetate & 0 & ud & 0.47 & ud & 0 & ud \\
\hline Phenolic content & 11 & nd & 56 & nd & 27 & nd \\
\hline Phenolic/alcoholic hydroxyls & 0.05 & nd & 0.53 & nd & 0.25 & nd \\
\hline Carbohydrate content & 38 & 17 & 19 & 0 & 0 & 0 \\
\hline Total aliphatic non-oxygenated & 24 & 35 & 12 & 31 & 18 & 55 \\
\hline Total aliphatic oxygenated & 66 & 52 & 66 & 48 & 63 & 34 \\
\hline Total aromatic & 10 & 13 & 22 & 21 & 19 & 12 \\
\hline
\end{tabular}

${ }^{a}$ Including $5 \% \alpha$-acylated units (together with major $\gamma$-acylation); 0 , values below the detection level of $2 \mathrm{D}$ NMR; nd, not determined; ud, undetermined due to zero division.

$40 \%$ of lignin units were $p$-coumaroylated (Table 1 ). A lower value was suggested by the $p$-coumarate/acetate ratio (a rough estimation due to the different nature of the signals integrated), most probably because of other acetyl substituents, e.g. in contaminating carbohydrates. Presence of the unusual diacylated $\beta-\beta^{\prime}$ structures $\left(\mathbf{B}^{\prime}\right)$ was suggested by their cross-signals in the spectra of underivatized and in vitro acetylated MWL, whose displacements were the same as those found in the A. sisalana spectra. The fact that acetylated $\beta-\beta^{\prime}$ structures were not detected by modified DFRC of this lignin (del Río et al., 2007b) suggests a high presence of $p$-coumaric acid as the acylating group in $M$. textilis lignin.

High predominance of $\beta-0-4^{\prime}$ substructures (95-100\%) was also found in the alkalilignin sample. No enrichment in resinol substructures was possible since these $\beta-\beta^{\prime}$ structures are absent from the $M$. textilis lignin. The broad signal with $\delta_{\mathrm{H}} / \delta_{\mathrm{C}} 7.0 / 129 \mathrm{ppm}$ pointed to the presence of H-type structures in this alkalilignin, as found in the $C$. sativa lignins discussed below, although the $\delta_{\mathrm{H}} /$ $\delta_{\mathrm{C}}$ values were not exactly the expected. However, the absence of similar signals in the MWL sample suggested that it could also correspond to a not yet assigned structure formed during the alkali treatment. The alkali treatment also resulted in a decrease of the lignin $S / G$ ratio.

\subsection{Characteristics of the C. sativa lignin}

The HSQC spectra of the $C$. sativa lignins are shown in Fig. 4, and their main characteristics are described in Table 1 . The aromatic region was characterized by the presence of cross-signals corresponding to the three types of lignin units. The $G$ units were predominant (H:G:S ratio of 12:49:39) in contrast with the A. sisalana and $M$. textilis lignins that were of the $S$ type (Table 1 ). The presence of $\mathrm{H}$ units and low $\mathrm{S} / \mathrm{G}$ ratio in $C$. sativa lignin had already been reported by analytical pyrolysis and DFRC (del Río et al., 2007b; Gutiérrez et al., 2006). The comparatively high phenolic content in this MWL (near 30\%) could be related to its higher content of $\mathrm{H}$ and $\mathrm{G}$ units, which can establish $\mathrm{C}_{3}$ and $\mathrm{C}_{5}$ inter-unit linkages leaving the hydroxyl group free.

The side-chain region also revealed significant differences compared with the other two lignins. First, $\beta-\beta^{\prime}$ resinol and phenyl- coumaran substructures involved a significant proportion of MWL side-chains, together with $\beta-O-4^{\prime}$ substructures (Table 1 ). As shown in Fig. 4a, two different $\mathbf{A}_{\boldsymbol{\beta}}$ cross-signals were found in this G-rich lignin depending of whether the second unit was an $S$ $\left(\delta_{\mathrm{H}} / \delta_{\mathrm{C}} 4.11 / 86.5 \mathrm{ppm}\right)$ or $\mathrm{G}$ unit $\left(\delta_{\mathrm{H}} / \delta_{\mathrm{C}} 4.28 / 84.3 \mathrm{ppm}\right)$. Moreover, this lignin was practically free of $\gamma$-acylating groups, as revealed by the absence of the $\mathbf{A}_{\beta}^{\prime}$ and $\mathbf{A}_{\gamma}^{\prime}$ cross-signals discussed above.

Finally, comparison of the MWL and alkalilignin spectra showed strong decreases of both the $S / G$ ratio (from 0.8 to 0.3 ) and the amount of $\beta-0-4^{\prime}$ substructures (from $64-69 \%$ to only $16 \%$ sidechains) due to the alkaline treatment.

\subsection{Comparison of acylation degree and structural characteristics of lignins}

When acylation degree was considered, the three MWL preparations were characterized by: (i) high degree of acetylation (nearly $80 \%$ ) at the side-chain $\gamma$-position (A. sisalana lignin); (ii) high $\gamma$-acylation degree (nearly $85 \%$ ) but including both acetyl and $p$-coumaroyl substituents ( $M$. textilis lignin); and (iii) absence of acylation (C. sativa lignin). The acylation degree (Table 1 ) was calculated by integrating the $\mathbf{A}_{\beta}^{\prime}$ and $\mathbf{A}_{\beta}$ cross-signals and, therefore, only represents the $\beta-O-4^{\prime}$ substructures. However, this seems reasonably correct since resinols are only formed from non-acylated monolignols, and spirodienones and phenylcoumarans were relatively minor substructures (2-9\% side-chains). Use of the $\mathbf{A}_{\gamma}^{\prime}$ integral for calculating the acylation degree could be preferred at first glance, since it includes also $\mathrm{H}_{\gamma}-\mathrm{C}_{\gamma}$ correlations in acylated phenylcoumaran and spirodienone substructures (although this is not the case for non-acylated $\mathbf{A}_{\gamma}$, since $\mathbf{C}_{\gamma}$ has different chemical shifts). Moreover, the broad $\mathbf{A}_{\gamma}$ cross-signal most probably includes other related signals (e.g. from carbohydrates), and it provided slightly underestimated acylation degrees. The fact that the $\mathbf{A}_{\beta}^{\prime}$ cross-signal partially overlapped with the same signal in structure-A including a G-type B-ring (see Section 2.7) did not result in strong interference given that the acylated lignins are characterized by a high $S / G$ ratio.

In addition to the above differences in the acylation pattern, the HSQC spectra also revealed structural differences between the 
three lignins. When lignin composition was considered, we found: (i) S-rich lignins in A. sisalana and M. textilis (over $80 \% \mathrm{~S}$ units) although the former with a higher $\mathrm{G}$ content; and (ii) G-rich lignin in C. sativa (near $50 \% \mathrm{G}$ units) with a significant proportion (over $10 \%$ ) of $\mathrm{H}$ units. When inter-unit linkages were considered, we found: (i) lignin with high predominance of $\beta-O-4^{\prime}$ linkages (over $90 \%$ side-chains) together with some spirodienones in M. textilis; (ii) lignin with high predominance of $\beta-0-4^{\prime}$ linkages (over $85 \%$ side-chains) and low amounts ( $2-5 \%$ side-chains) of resinol, spirodienone and phenylcoumaran linkages in A. sisalana; and (iii) lignin with significant amount of resinol (over $20 \%$ side-chains) and phenylcoumaran (9\%) linkages, together with the major $\beta-O-4^{\prime}$ linkages, in C. sativa.

To extend the correlations between acylation degree and lignin composition and inter-unit linkages, additional information was collected from HSQC spectra of MWL from six additional plant species (unpublished). Fig. 6 presents the $S / G$ ratio and the relative amount of $\beta-\beta^{\prime}$ side-chains against the acylation degree in the following eight plant species (from different botanical groups): $C$. sativa (Rosales); Eucalyptus globulus Labill. (eucalypt, Myrtales); Corchorus capsularis L. (jute, Malvales); Cocos nucifera L. (palm tree, Arecales), H. cannabinus L. (kenaf, Malvales), A. sisalana (Asparagales), Ananas erectifolius L.B. Smith (curaua, Poales) and M. textilis (Zingiberales). Moreover, no natural acylation was found in the Gtype MWL from Picea abies (L.) Karst. (Norway spruce, Coniferales). It is possible to see that the general tendency found in the three model lignins described here is maintained in the other lignins, i.e. highly-acylated lignins are often characterized by a high S/G ratio, and a low percentage of $\beta-\beta^{\prime}$ linkages, whereas the opposite often occurred in scarcely acylated lignins.

\subsection{Monolignol acylation as a mechanism to control lignin structure}

It has been shown that lignin acylation, including acetylation and $p$-coumaroylation, is produced at the monolignol level (del Río et al., 2007b; Lu and Ralph, 2002, 2005; Lu et al., 2004; Morreel et al., 2004). This was demonstrated by the detection of mono- and diacylated $\beta-\beta^{\prime}$ tetrahydrofuran structures in plant lignin, including the structure $\mathbf{B}^{\prime}$ discussed above, using modified DFRC and 2D NMR. These structures must originate from the $\beta-\beta^{\prime}$ homo-

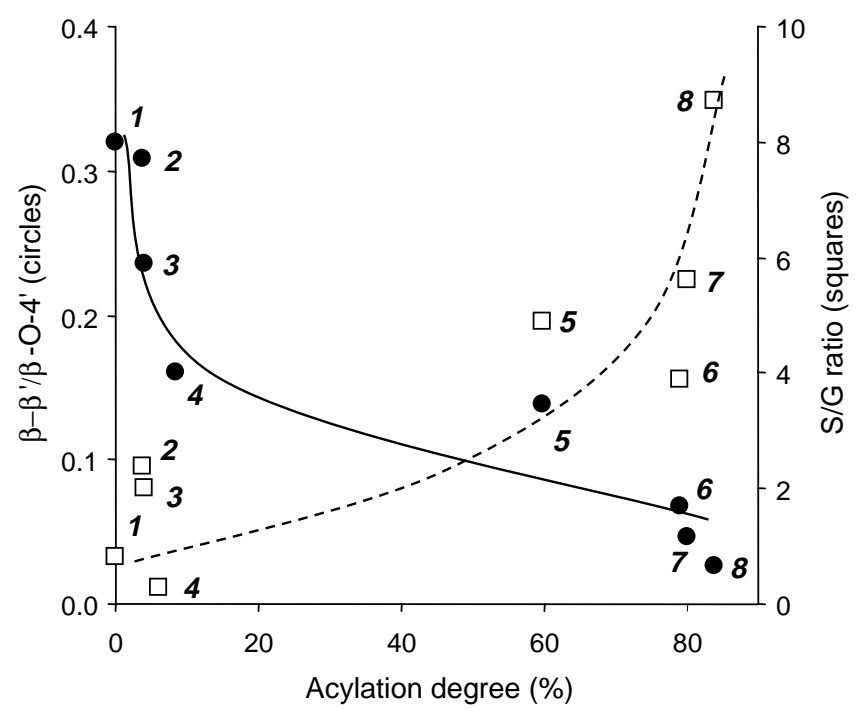

Fig. 6. Differences in native lignin composition ( $S / G$ ratio, white squares and dashed tendency line) and inter-unit linkages $\left(\beta-\beta^{\prime} / \beta-O-4^{\prime}\right.$ ratio, black circles and continuous line) as a function of the acylation degree in MWL from 8 plant species analyzed by HSQC NMR: C. sativa (1), E. globulus (2), C. capsularis (3), C. nucifera (4), H. cannabinus (5), A. sisalana (6), A. erectifolius (7), and M. textilis (8). and cross-coupling of the two sinapyl (acylated and non-acylated) monolignols. Heteronuclear multiple bond correlation (HMBC) between the ester carbonyl carbon and the lignin $\gamma$-protons (Ralph et al., 1994) could not be observed by the authors, but lignin acylation at the $\gamma$-position is indisputably shown by the strong displacement of the $\mathrm{H}_{\gamma}-\mathrm{C}_{\gamma}$ correlation signal in the HSQC spectra and the structure of the modified-DFRC products (del Río et al., 2007b).

The above conclusion received additional support from the chromatographic detection of $\gamma$-acetylated sinapyl alcohol in the acetone extracts from two of the nonwoody fibers analyzed here (Fig. 7a) based on its mass spectrum (Fig. 7b). The abundance of the $\gamma$-acetylated sinapyl alcohol was roughly estimated by
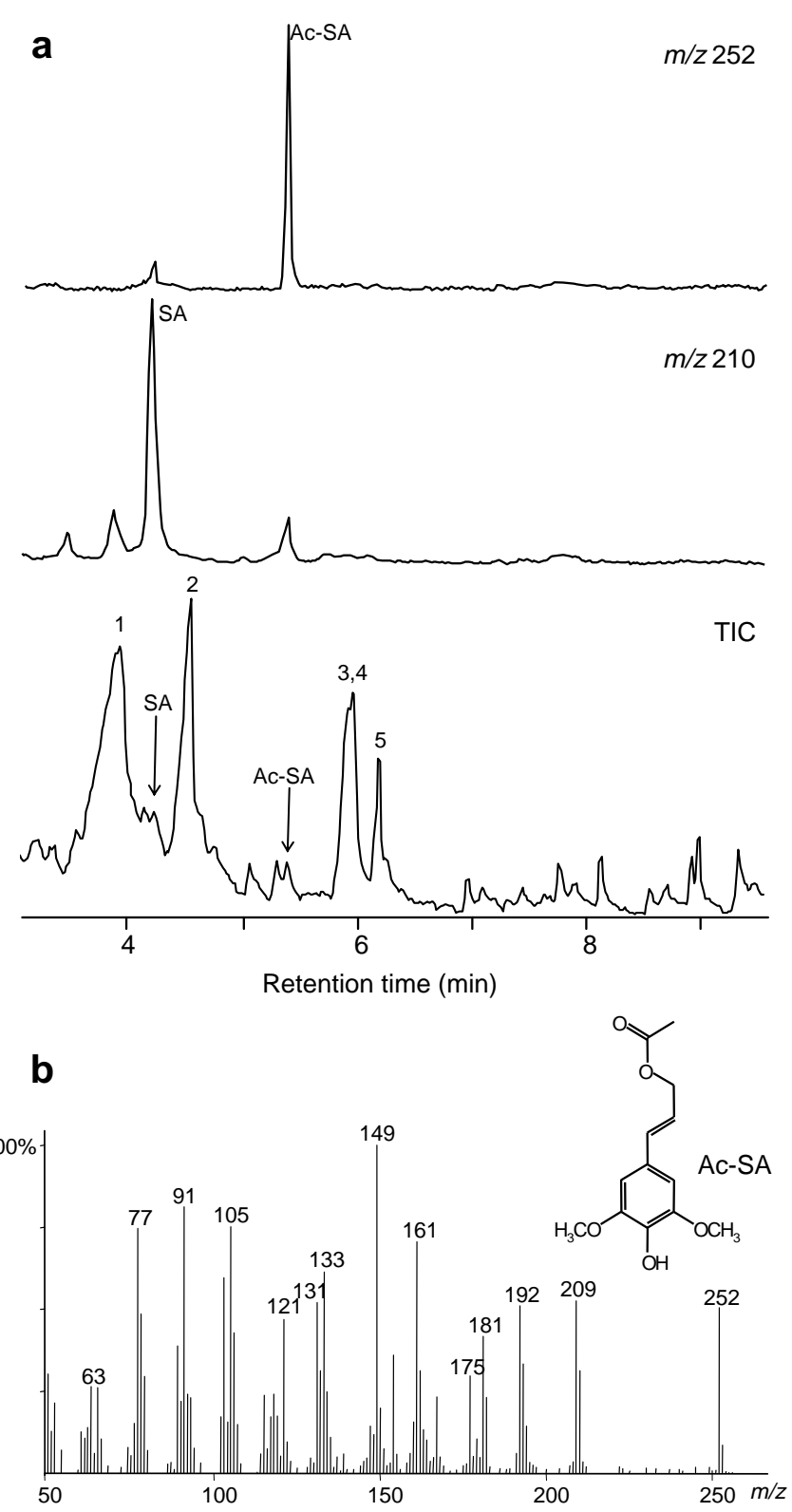

Fig. 7. GC-MS analysis of the M. textilis extractives. (a) Expanded region of the total-ion chromatogram (TIC) from the acetone extract of the whole fiber showing the presence of sinapyl acetate (Ac-SA) and free sinapyl alcohol (SA) peaks together with other extractives (1, $p$-coumaric acid; 2 , palmitic acid; 3, linoleic acid; 4 , oleic acid; and 5, stearic acid); and reconstructed chromatograms based on selected ions, $m / z 252$ and $m / z 210$, enabling localization of the Ac-SA and SA peaks, respectively. (b) Mass spectrum of the Ac-SA peak enabling its identification as $\gamma$-acetylated sinapyl alcohol. 
GC-MS as $50 \%$ of the normal (non-acylated) monolignol in A. sisalana, and around $33 \%$ of the normal monolignol in M. textilis. Moreover, mono-acylated $\beta-\beta^{\prime}$ di- and tri-lignols have been identified in the methanol extract from poplar wood (Morreel et al., 2004) derived from $\gamma$-p-hydroxybenzoylated sinapyl alcohol. It is also interesting that changes in the extent of poplar lignin acylation have been recently described in trees growing under variable environmental conditions (Pitre et al., 2007). Therefore, it is possible to envision monolignol acylation as a mechanism to regulate the structure of lignin in different nonwoody, and maybe other, angiosperms as postulated below.

\subsection{Acylation and formation of S-rich lignins}

During screening for acylated lignins in woody and nonwoody plants (del Río et al., 2007b) we already observed that acylation was higher in angiosperms producing S-rich lignins, and the same had been reported by others (Lu and Ralph, 1999, 2002). However, at least in some cases, the situation could be described in the opposite way, i.e. maybe some of these lignins are rich in $S$ units because sinapyl alcohol is acylated during precursor biosynthesis. It is known that sinapyl alcohol is much less efficiently oxidized by plant peroxidases than coniferyl alcohol and, since S-type phenols have lower redox potentials than G-type phenols, this seems due to steric hindrances at the catalytic site. Participation of redox mediators oxidizing substrates at distance from the enzyme could overcome these steric obstacles. From its discovery in laccase studies (Bourbonnais and Paice, 1990), the enzyme-mediator concept raised high interest, and $p$-coumaric acid appeared as one of the best mediators (Cañas et al., 2007). The ability of $p$-coumaric acid promoting in vitro peroxidase oxidation of sinapyl alcohol has been reported (Takahama et al., 1996). Therefore, p-coumaroylation could be seen as a mechanism to facilitate the enzymatic oxidation of sinapyl alcohol resulting in synthesis of S-rich lignins by some plants.

However, the mediating role of $p$-coumaric acid could not be shown in plant cell suspensions, maybe because of peroxidase inactivation at high doses of sinapyl p-coumarate (Grabber, 2005; Grabber and Lu, 2007), and the effect of monolignol acetylation, which is also associated to the presence of S-rich lignins, is still to be established. Moreover, some exceptions to the very preferential acylation of S lignin units have been found, e.g. the lignin of $A$. erectifolius has similar percentages of acetylated $S(46 \%)$ and $G$ (50\%) units as shown by modified DFRC, although $p$-coumaroylation concentrates on the $S$ units (15\%) and $G$ units are practically free of $p$-coumaric esters (del Río et al., 2008). Strong selectivity for $p$-coumaroylation of $\mathrm{S}$ units was already reported by $\mathrm{Lu}$ and Ralph (1999) in Bambusa (bamboo) and Z. mays (maize) lignins.<smiles>OC/C=C/c1ccc(O)cc1</smiles><smiles>COc1cc(/C=C/CO)ccc1O</smiles><smiles>COc1cc(/C=C/CO)cc(OC)c1O</smiles><smiles>[R]OC/C=C/C1C(C)(C)C2(C)CC(C)(C)C1(C)C2</smiles>

$\mathrm{H}$
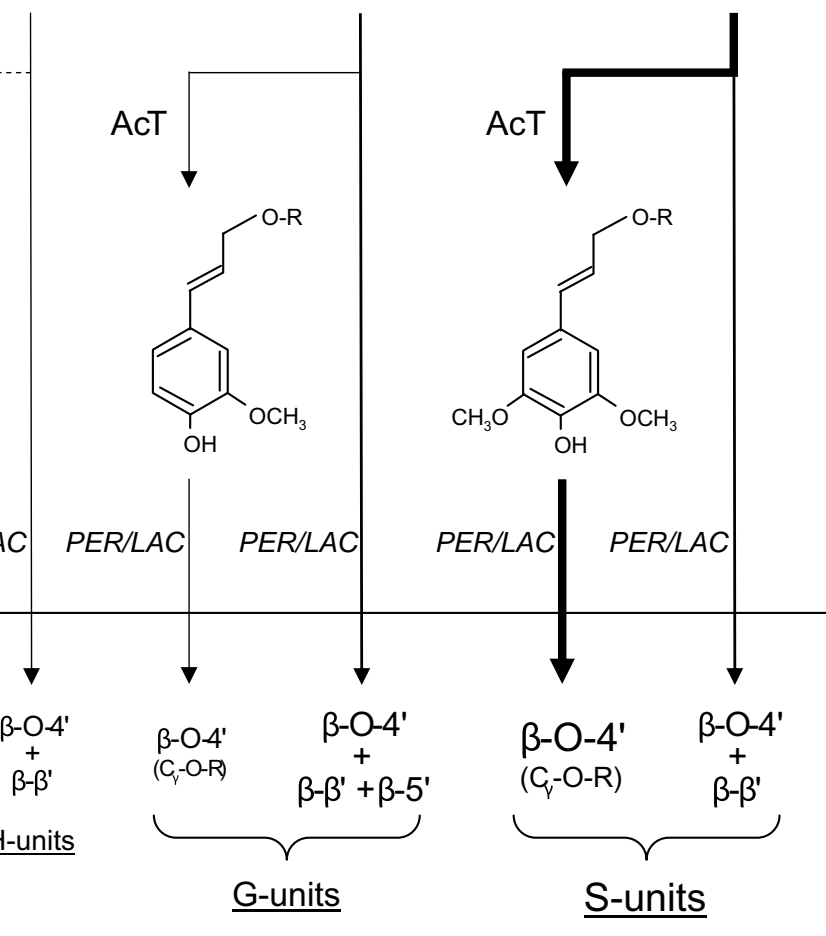
$\mathrm{OCH}_{3}$

\section{LIGNIN POLYMER}

Fig. 8. Hypothetical scheme of the regulation of lignin structure in nonwoody angiosperms including: (i) hypothetical acyltransferase (AcT) partially acylating coniferyl and sinapyl alcohols; (ii) oxidation of "normal" and $\mathrm{C}_{\gamma}$-acylated monolignols by cell-wall peroxidases (PER) and/or laccases (LAC); and (iii) radical coupling, resulting in highlyetherified ( $\beta-O-4^{\prime}$ linked) S-type lignin in plants that strongly acylate monolignols $(R$, acetyl $/ p$-coumaroyl). 
As discussed below, still unknown acyltranferases are probably involved in monolignol acylation, and an enzyme candidate with higher affinity towards sinapyl alcohol than towards coniferyl alcohol has been found (X. Yu, Brookhaven National Laboratory, personal communication). This could be an alternative explanation to the higher abundance of acylated $S$ units than $G$ units in many lignins, especially in the case of acetylation that is not expected to increase the facility of sinapyl alcohol to be incorporated to lignin.

\subsection{Acylation modifies lignin inter-unit linkages}

It has been reported that in vitro peroxidase- $\mathrm{H}_{2} \mathrm{O}_{2}$ oxidation of equimolar amounts of sinapyl alcohol and $\gamma$-acylated (acetylated or $p$-coumaroylated) sinapyl alcohol produced equal amounts of the expected $\beta-\beta^{\prime}$ homo-coupled and cross-coupled products, indicating that the reaction is insensitive to $\gamma$-acylation (Lu and Ralph, 2005; Lu et al., 2004). However, in the lignins analyzed here, strong acylation resulted in extremely low abundances of $\beta-\beta^{\prime}$ linkages. The depressing effect of monolignol acylation on the formation of $\beta-\beta^{\prime}$ structures not only affected the normal resinol-type structures, which require free $\mathrm{C}_{\gamma}-\mathrm{OH}$ in both monomers for cyclization after initial $\beta-\beta^{\prime}$ coupling. Also the unusual acylated $\beta-\beta^{\prime}$ tetrahydrofuran structures presented very low abundances (only around $2 \%$ side-chains). More intriguingly, only one of the two possible stereoisomers from homo-coupling of acylated sinapyl alcohol has been found in plant lignins being different from that obtained after in vitro coupling (Lu and Ralph, 2005).

It is interesting that syringaresinol, which is nearly the only resinol in some S-rich lignins (Rencoret et al., 2008a), must be necessarily an initiation point in lignin polymerization, additional units being incorporated to the free phenolic groups of the dilignol. Despite the postulated existence of proteins with "dirigent sites" controlling lignin polymerization, which would be more abundant at the cell-wall lignification sites (Davin and Lewis, 2005), the only dirigent-type protein fully characterized up to date is involved in the biosynthesis of a resinol lignan (Davin et al., 1997). However, it is possible to imagine that in plants producing S-type lignin a mechanism exist (dirigent-type protein or other) to initiate lignification at specific sites of the cell-wall by formation of syringaresinol dilignols. This mechanism should be regiospecific promoting the $\beta-\beta^{\prime}$ linkage (but not stereospecific) and would act in such a way that $\gamma$-acylated monolignols (and especially the more bulky $\gamma$-p-coumaroylated ones) are discarded and would not participate in the coupling reaction. In this way, acylation could act as a control mechanism reducing the amount of $\beta-\beta^{\prime}$ linkages and increasing that of $\beta-O-4^{\prime}$ ethers, as found in the $A$. sisalana and especially in the $M$. textilis lignins described here.

\subsection{Acetyl/p-coumaroyl transferases controlling monolignol polymerization}

Fig. 8 shows the proposed last steps of lignin biosynthesis including acylation. Once the primary monolignols ( $p$-hydroxycinnamyl, coniferyl and sinapyl alcohols) are formed (Boerjan et al., 2003), they can be acylated at the $\gamma$-carbon of the side-chain by an acyltransferase (AcT) that would use an activated acid ( $R$-S$\mathrm{CoA}$ ) to form the corresponding acylated secondary monolignols. Interestingly, a $p$-hydroxy-cinnamoyltransferase forming $p$-coumaric acid esters has been recently incorporated to the set of enzymes involved in lignin biosynthesis, the corresponding ester being the substrate of $p$-coumarate-3-hydroxylase (Hoffmann et al., 2005). However, the acyltransferases involved in monolignol acetylation/p-coumaroylation are still under investigation (Marita et al., 2007).
Once the primary and secondary monolignols are formed and exported to cell-wall space, they can readily undergo peroxidase and/or laccase oxidation resulting in radical coupling to form the lignin polymer. Acylated monolignols would not form (or only form minor) $\beta-\beta^{\prime}$ substructures and, therefore, $\beta-O-4$ linked $S$-rich lignins will be formed, as discussed above. The AcT could be seen as a sort of switch regulating the production and flux of the acylated and non-acylated monolignols, and, in last instance, controlling the structure of the lignin polymer.

Studies on lignin acylation mechanisms should incorporate to current research programs for tailoring the structure of lignin to obtain raw materials more amenable for paper pulp manufacture, animal feeding or bioethanol production (Ralph, 2007; Vanholme et al., 2008).

\section{Conclusions}

2D NMR of lignins from several angiosperms revealed different molecular structures, in terms of aromatic units and inter-unit linkages, and different $\gamma$-acylation types (acetate and/or $p$-coumarate esters) and extents (up to more that $90 \%$ of units). Moreover, a correspondence between the molecular structure of these lignins and their degree of acylation was found. Some of the $\beta-\beta^{\prime}$-linked lignin substructures identified showed that acylation is produced at the monolignol level. Direct evidence was also provided by GC-MS identification of $\gamma$-acetylated sinapyl alcohol among the plant extractives. Taking the above findings together, it is proposed that some angiosperms use monolignol acylation as a mechanism to regulate the structure of lignin. In this way, acylation of monolignols would result in lower presence of resinols and other $\beta-\beta^{\prime}$ inter-unit linkages in S-rich lignins, promoting formation of a highly-etherified ( $\beta-O-4^{\prime}$ linked) and more labile lignin polymer. In contrast, low (or null) acylation degrees would result in lignins with higher content of $\beta-\beta^{\prime}$ carbon-carbon inter-unit linkages, that will be more recalcitrant towards chemical and/or biological degradation.

\section{Experimental}

\subsection{Lignin samples}

Plant fibers were provided by the CELESA mill in Tortosa (Tarragona, Spain). Bast fibers from $C$. sativa and leaf fibers from $A$. sisalana and $M$. textilis are used for manufacturing high-quality pulps for specialty papers. Fibers were ground to sawdust using a knife mill (Janke and Kunkel $\mathrm{GmbH}$ ), and extracted with acetone ( $8 \mathrm{~h}$ in a Soxhlet) and hot-water $\left(3 \mathrm{~h}\right.$ at $\left.100^{\circ} \mathrm{C}\right)$. Then, they were finely milled for $150 \mathrm{~h}$ using a ball mill (Retsch) with a $250-\mathrm{ml}$ jar containing 12 balls of $2 \mathrm{~cm}$ diameter. MWL was extracted with dioxane-water (9:1), precipitated and purified (Björkman, 1956) with a final yield of 5-15\% referred to Klason lignin, estimated according to rule T222 om-88 (Tappi, 2004). Underivatized and acetylated MWL, after $48 \mathrm{~h}$ treatment in acetic anhydride-pyridine $(1: 2)$, were analyzed as described below. Alkalilignins were extracted from the above plant materials under alkaline conditions, using $0.2 \mathrm{M} \mathrm{NaOH}$ at $120^{\circ} \mathrm{C}$, precipitated at acidic $\mathrm{pH}$, and washed with acidulated, resulting in much higher yield than obtained for MWL (del Río et al., 2007a).

\subsection{D NMR spectroscopy}

Two-dimensional NMR spectra were recorded at $25^{\circ} \mathrm{C}$ on a Bruker AVANCE $500 \mathrm{MHz}$ using a z-gradient triple resonance probe. Lignins $\left(40 \mathrm{mg}\right.$ ) were dissolved in $0.75 \mathrm{ml}$ of DMSO- $d_{6}$, and spectra were recorded in HSQC experiments. The spectral widths for the 
HSQC spectra were $5000 \mathrm{~Hz}$ and $25625 \mathrm{~Hz}$ for the ${ }^{1} \mathrm{H}$ and ${ }^{13} \mathrm{C}$ dimensions, respectively. The number of collected complex points was 2048 for the ${ }^{1} \mathrm{H}$-dimension with a recycle delay of $5 \mathrm{~s}$. The number of transients was 64 , and 256 time increments were always recorded in the ${ }^{13} \mathrm{C}$-dimension. The $J$-coupling evolution delay was set to $3.2 \mathrm{~ms}$. A squared cosine-bell apodization function was applied in both dimensions. Prior to Fourier transform the data matrixes were zero filled up to 1024 points in the ${ }^{13} \mathrm{C}$-dimension. The central solvent peak was used as an internal reference $\left(\delta_{\mathrm{H}} / \delta_{\mathrm{C}}\right.$ $2.50 / 40.1 \mathrm{ppm})$. Signals were assigned by comparison with the literature (Balakshin et al., 2003; Capanema et al., 2001, 2004, 2005; Ibarra et al., 2007a,b; Liitiä et al., 2003; Ralph et al., 1999, 2006, 2004).

A semiquantitative analysis of the HSQC cross-signal intensities was performed (Heikkinen et al., 2003; Zhang and Gellerstedt, 2007). Volume integrations were performed separately for the different regions of the spectra, which contain cross-signals of chemically analogous carbon-proton pairs. For these signals, the ${ }^{1} J_{\mathrm{CH}}$ coupling value is relatively similar and suited for a semiquantitative estimation of the different $\mathrm{H}-\mathrm{C}$ correlations. In the aliphaticoxygenated region, inter-unit linkages were estimated from the $\mathrm{H}_{\alpha}-\mathrm{C}_{\alpha}$ correlations, and the relative abundance of side-chains involved in each inter-unit linkage type were calculated. The H:G:S ratio of lignins was estimated based on the aromatic $\mathrm{H}_{2,6}-\mathrm{C}_{2,6}$ correlations of $\mathrm{H}$ and $\mathrm{S}$ units, and the $\mathrm{H}_{2}-\mathrm{C}_{2}$ plus $\mathrm{H}_{6}-\mathrm{C}_{6}$ correlations of $\mathrm{G}$ units. The $p$-coumarate content of lignin was estimated from the intensity of the corresponding $\mathrm{H}_{2,6}-\mathrm{C}_{2,6}$ correlation referred to the total intensity of the above $\mathrm{H}, \mathrm{G}$ and $\mathrm{S}$ signals. The intensity of the above $p$-coumarate aromatic signal (divided by 2 since it corresponds to $\mathrm{H}_{2}$ and $\mathrm{H}_{6}$ correlations) was referred to the intensity of the alcoholic acetate signal (divided by 3 since it corresponds to three protons) to obtain the $p$-coumarate/acetate ratio. The amount of phenolic and alcoholic hydroxyls in MWL was estimated by integrating the methyl signals of the corresponding acetates, after in vitro acetylation (compared with underivatized $\mathrm{MWL}$ ). The percentage of phenolic structures was calculated by referring the phenolic acetate signal to the total number of aromatic rings $(\mathrm{H}+\mathrm{G}+\mathrm{S}+p$-coumaric acid $)$. The latter was estimated from the intensity of the methoxyl signal, taking into account the $\mathrm{H}: \mathrm{G}: \mathrm{S}$ ratio and content of $p$-coumaric acid (referred to lignin) of the sample, and the number of methoxyls of $\mathrm{H}$ (none), $\mathrm{G}$ (one), $\mathrm{S}$ (two) and $p$-coumaric acid (none) aromatic rings.

\subsection{GC-MS analysis of extractives}

Fiber extractives isolated with acetone (see Section 4.1) were analyzed by GC-MS using a Varian Saturn 2000 chromatograph coupled to an ion-trap detector, and equipped with a fused silica capillary column (DB-5HT; $15 \mathrm{~m} \times 0.25 \mathrm{~mm}$ i.d., $0.1 \mu \mathrm{m}$ film thickness). The oven was heated from $120^{\circ} \mathrm{C}(1 \mathrm{~min})$ to $380^{\circ} \mathrm{C}$ $(5 \mathrm{~min})$ at $10^{\circ} \mathrm{C} \mathrm{min}^{-1}$. The injector and transfer line temperatures were set at $300^{\circ} \mathrm{C}$ and $350{ }^{\circ} \mathrm{C}$, respectively. Helium was used as the carrier gas and the injection was performed in splitless mode. Peaks were quantified by area using standards for calibration.

\section{Note added in proof}

After submitting the present manuscript a paper was published (on-line) by R. Hatfield, J. Ralph and J.H. Grabber ("A potential role of sinapyl p-coumarate as a radical transfer mechanism in grass lignin formation" Planta. 2008. doi:10.1007/s00425-008-0791-4) demonstrating that, as suggested in Section 2.10 of the present article, sinapyl p-coumarate can act as a radical transfer mechanism facilitating polymerization of S-type lignin.

\section{Acknowledgements}

The study was funded by the BIORENEW EU-project (NMP2-CT2006-26456), and the Spanish projects BIO2005-3569, BIO200728719-E, BIO2007-28720-E, BIO2008-01533, AGL2005-01748 and AGL2008-00709/FOR. CELESA (Tortosa, Spain) is acknowledged for providing the plant materials analyzed. J.I. Santos (CIB, CSIC, Madrid) is acknowledged for help in the NMR studies. D.I. and J.R. thank I3P Fellowships of the Spanish CSIC, and G.M. thanks the Spanish MEC for an FPI Fellowship.

\section{References}

Balakshin, M., Capanema, E., Chen, C.-L., Gratzl, J., Kirkman, A., Gracz, H., 2001. Biobleaching of pulp with dioxygen in the laccase-mediator system - reaction mechanisms for degradation of residual lignin. J. Mol. Catal. B Enzym. 13, 1-16.

Balakshin, M.Y., Capanema, E.A., Chen, C.-L., Gracz, H.S., 2003. Elucidation of the structures of residual and dissolved pine kraft lignins using an HMQC NMR technique. J. Agric. Food Chem. 51, 6116-6127.

Balakshin, M.Y., Capanema, E.A., Goldfarb, B., Frampton, J., Kadla, J.F., 2005. NMR studies on Fraser fir Abies fraseri (Pursh) Poir. Lignins Holzforschung 59, 488496.

Björkman, A., 1956. Studies on finely divided wood. Part I. Extraction of lignin with neutral solvents. Sven. Papperstidn. 13, 477-485.

Boerjan, W., Ralph, J., Baucher, M., 2003. Lignin biosynthesis. Annu. Rev. Plant Biol. 54, 519-546.

Bourbonnais, R., Paice, M.G., 1990. Oxidation of non-phenolic substrates. An expanded role for laccase in lignin biodegradation. FEBS Lett. 267, 99-102.

Bunzel, M., Ralph, J., 2006. NMR characterization of lignins isolated from fruit and vegetable insoluble dietary fiber. J. Agric. Food Chem. 54, 8352-8361.

Cañas, A., Alcalde, M., Plou, F.J., Martínez, M.J., Martínez, A.T., Camarero, S., 2007. Transformation of polycyclic aromatic hydrocarbons by laccase is strongly enhanced by phenolic compounds present in soil. Environ. Sci. Technol. 41, 2964-2971.

Capanema, E.A., Balakshin, M.Y., Chen, C.-L., Gratzl, J.S., Gracz, H., 2001. Structural analysis of residual and technical lignins by ${ }^{1} \mathrm{H}-{ }^{13} \mathrm{C}$ correlation 2D NMRspectroscopy. Holzforschung 55, 302-308.

Capanema, E.A., Balakshin, M.Y., Kadla, J.F., 2004. A comprehensive approach for quantitative lignin characterization by NMR spectroscopy. J. Agric. Food Chem. $52,1850-1860$

Capanema, E.A., Balakshin, M.Y., Kadla, J.F., 2005. Quantitative characterization of a hardwood milled wood lignin by nuclear magnetic resonance spectroscopy. J. Agric. Food Chem. 53, 9639-9649.

Chen, C.-L., Capanema, E.A., Gracz, H.S., 2003. Comparative studies on the delignification of pine kraft-anthraquinone pulp with hydrogen peroxide by binucleus Mn(IV) complex catalysis. J. Agric. Food Chem. 51, 6223-6232.

Crestini, C., Argyropoulos, D.S., 1997. Structural analysis of wheat straw lignin by quantitative ${ }^{31} \mathrm{P}$ and $2 \mathrm{D}$ NMR spectroscopy. The occurrence of ester bonds and $\alpha-0-4$ substructures. J. Agric. Food Chem. 45, 1212-1219.

Davin, L.B., Lewis, N.G., 2005. Lignin primary structures and dirigent sites. Curr. Opin. Biotechnol. 16, 407-415.

Davin, L.B., Wang, H.B., Crowell, A.L., Bedgar, D.L., Martin, D.M., Sarkanen, S., Lewis N.G., 1997. Stereoselective bimolecular phenoxy radical coupling by an auxiliary (dirigent) protein without an active center. Science $275,362-366$.

del Río, J.C., Gutiérrez, A., 2006. Chemical composition of abaca (Musa textilis) leaf fibers used for manufacturing of high quality paper pulps. J. Agric. Food Chem. $54,4600-4610$

del Río, J.C., Gutiérrez, A., Martínez, A.T., 2004. Identifying acetylated lignin units in non-wood fibers using pyrolysis-gas chromatography/mass spectrometry. Rapid Commun. Mass Spectrom. 18, 1181-1185.

del Río, J.C., Gutiérrez, A., Rodríguez, I.M., Ibarra, D., Martínez, A.T., 2007a. Composition of non-woody plant lignins and cinnamic acids by Py-GC/MS, Py/TMAH and FTIR. J. Anal. Appl. Pyrolysis 79, 39-46.

del Río, J.C., Marques, G., Rencoret, J., Martínez, A.T., Gutiérrez, A., 2007b. Occurrence of naturally acetylated lignin units. J. Agric. Food Chem. 55, 5461-5468.

del Río, J.C., Martínez, A.T., Gutiérrez, A., 2007c. Presence of 5-hydroxyguaiacyl units as native lignin constituents in plants as seen by Py-GC/MS. J. Anal. Appl. Pyrolysis 79, 33-38.

del Río, J.C., Rencoret, J., Marques, G., Gutiérrez, A., Ibarra, D., Santos, J.I., JiménezBarbero, J., Martínez, A.T., 2008. Highly acylated (acetylated and/or pcoumaroylated) native lignins from diverse herbaceous plants. J. Agric. Food Chem. 2008. doi:10.1021/jf800806h.

Ede, R.M., Brunow, G., 1992. Application of two-dimensional homonuclear and heteronuclear correlation NMR spectroscopy to wood lignin structure determination. J. Org. Chem. 57, 1477-1480.

Fengel, D., Wegener, G., 1984. Wood: Chemistry, Ultrastructure Reactions. De Gruyter, Berlin.

Fukagawa, N., Meshitsuka, G., Ishizu, A., 1991. A 2-dimensional NMR-study of birch milled wood lignin. J. Wood Chem. Technol. 11, 373-396.

Galkin, S., Ammalahti, E., Kilpeläinen, I., Brunow, G., Hatakka, A., 1997. Characterisation of milled wood lignin from reed canary grass (Phalaris arundinacea). Holzforschung 51, 130-134. 
Grabber, J.H., 2005. How do lignin composition, structure, and cross-linking affect degradability? A review of cell wall model studies. Crop Sci. 45, 820-831.

Grabber, J.H., Lu, F., 2007. Formation of syringyl-rich lignins in maize as influenced by feruloylated xylans and $p$-coumaroylated monolignols. Planta 226, 741-751.

Gutiérrez, A., Rodriguez, I.M., del Río, J.C., 2006. Chemical characterization of lignin and lipid fractions in industrial hemp bast fibers used for manufacturing highquality paper pulps. J. Agric. Food Chem. 54, 2138-2144.

Heikkinen, S., Toikka, M.M., Karhunen, P.T., Kilpeläinen, I.A., 2003. Quantitative 2D HSQC (Q-HSQC) via suppression of J-dependence of polarization transfer in NMR spectroscopy: Application to wood lignin. J. Am. Chem. Soc. 125, 4362-4367.

Higuchi, T., 1997. Biochemistry and Molecular Biology of Wood. Springer-Verlag, London.

Hoffmann, L., Besseau, S., Geoffroy, P., Ritzenthaler, C., Meyer, D., Lapierre, C., Pollet, B., Legrand, M., 2005. Acyltransferase-catalysed $p$-coumarate ester formation is a committed step of lignin biosynthesis. Plant Biosyst. 139, 50-53.

Holtman, K.M., Chang, H.M., Jameel, H., Kadla, J.F., 2006. Quantitative ${ }^{13} \mathrm{C}$ NMR characterization of milled wood lignins isolated by different milling techniques. J. Wood Chem. Technol. 26, 21-34.

Ibarra, D., Chávez, M.I., Rencoret, J., del Río, J.C., Gutiérrez, A., Romero, J., Camarero, S., Martinez, M.J., Jiménez-Barbero, J., Martínez, A.T., 2007a. Lignin modification during Eucalyptus globulus kraft pulping followed by totally chlorine free bleaching: A two-dimensional nuclear magnetic resonance, Fourier transform infrared, and pyrolysis-gas chromatography/mass spectrometry study. J. Agric. Food Chem. 55, 3477-3499.

Ibarra, D., Chávez, M.I., Rencoret, J., del Río, J.C., Gutiérrez, A., Romero, J., Camarero, S., Martínez, M.J., Jimenez-Barbero, J. Martínez, A.T, 2007b. Structural modification of eucalypt pulp lignin in a totally chlorine free bleaching sequence including a laccase-mediator stage. Holzforschung 61, 634-646.

Karhunen, P., Rummakko, P., Sipila, J., Brunow, G., Kilpeläinen, I., 1995. Dibenzodioxocins - a novel type of linkage in softwood lignins. Tetrahedron Lett. 36, 169-170.

Landucci, L.L., Deka, G.C., Roy, D.N., 1992. A 13C NMR study of milled wood lignins from hybrid Salix clones. Holzforschung 46, 505-511.

Liitiä, T.M., Maunu, S.L., Hortling, B., Toikka, M., Kilpeläinen, I., 2003. Analysis of technical lignins by two- and three-dimensional NMR spectroscopy. J. Agric. Food Chem. 51, 2136-2143.

Lu, F.C., Ralph, J., 1999. Detection and determination of $p$-coumaroylated units in lignins. J. Agric. Food Chem. 47, 1988-1992.

Lu, F., Ralph, J., 2002. Preliminary evidence for sinapyl acetate as a lignin monomer in kenaf. Chem. Commun., 90-91.

Lu, F., Ralph, J., 2005. Novel $\beta$ - $\beta$-structures in lignins incorporating acylated monolignols. Appita, 233-237.

Lu, F.C., Ralph, J., Morreel, K., Messens, E., Boerjan, W., 2004. Preparation and relevance of a cross-coupling product between sinapyl alcohol and sinapyl $p$ hydroxybenzoate. Org. Biomol. Chem. 2, 2888-2890.

Marita, J.M., Hatfield, R.D., Frost, K.E., 2007. Lignin acylation in grasses. Abs. Plant Biol. Bot. Congr., Chicago 8-11 (July), 106.

Morreel, K., Ralph, J., Kim, H., Lu, F.C., Goeminne, G., Ralph, S., Messens, E., Boerjan, W., 2004. Profiling of oligolignols reveals monolignol coupling conditions in lignifying poplar xylem. Plant Physiol. 136, 3537-3549.

Pitre, F.E., Pollet, B., Lafarguette, F., Cooke, J.E., MacKay, J.J., Lapierre, C., 2007. Effects of increased nitrogen supply on the lignification of poplar wood. J. Agric. Food Chem. 55, 10306-10314.

Ralph, J., 1996. An unusual lignin from kenaf. J. Nat. Prod. 59, 341-342.
Ralph, J., 2007. Perturbing lignification. In: Entwistle, K., Harris, P.J., Walker, J. (Eds.), The Compromised Wood Workshop. University of Canterbury, Christchurch, NZ, pp. 85-112.

Ralph, J., Hatfield, R.D., Quideau, S., Helm, R.F., Grabber, J.H., Jung, H.-J.G., 1994. Pathway of $p$-coumaric acid incorporation into maize lignin as revealed by NMR. J. Am. Chem. Soc. 116, 9448-9456.

Ralph, J., Marita, J.M., Ralph, S.A., Hatfield, R.D., Lu, F., Ede, R.M., Peng, J., Quideau, S., Helm, R.F., Grabber, J.H., Kim, H., Jimenez-Monteon, G., Zhang, Y., Jung, H.-J.G., Landucci, L.L., MacKay, J.J., Sederoff, R.R., Chapple, C., Boudet, A.M., 1999. Solution-state NMR of lignin. In: Argyropoulos, D.S. (Ed.), Advances in Lignocellulosics Characterization. Tappi Press, Atlanta, pp. 55-108.

Ralph, S.A., Ralph, J., Landucci, L., 2004. NMR Database of Lignin and Cell Wall Model Compounds. US Forest Prod. Lab., One Gifford Pinchot Dr., Madison, WI 53705, <http://ars.usda.gov/Services/docs.htm?docid=10491> (accessed July 2006).

Ralph, J., Akiyama, T., Kim, H., Lu, F.C., Schatz, P.F., Marita, J.M., Ralph, S.A., Reddy, M.S.S., Chen, F., Dixon, R.A., 2006. Effects of coumarate 3-hydroxylase downregulation on lignin structure. J. Biol. Chem. 281, 8843-8853.

Rencoret, J., Marques, G., Gutiérrez, A., Ibarra, D., Li, J., Gellerstedt, G., Santos, J.I., Jiménez-Barbero, J., Martínez, A.T., del Río, J.C., 2008a. Structural characterization of milled wood lignin from different Eucalypt species. Holzforschung 62, 514-526.

Rencoret, J., Marques, G., Gutiérrez, A., Nieto, L., Jiménez-Barbero, J., Martínez, A.T., del Río, J.C., 2008b. In situ analysis of lignin by 2D NMR of milled wood (Eucalyptus globulus and Picea abies) and non-woody (Agave sisalana) plant materials at the gel state. Proc. EWLP'2008, Stockholm, KTH, pp. 340-343.

Smith, D.C.C., 1955a. Ester groups in lignin. Nature 176, 267-268.

Smith, D.C.C., 1955b. P-Hydroxybenzoate groups in the lignin of aspen (Populus tremula). J. Chem. Soc., 2347.

Sun, R., Fang, J.M., Tomkinson, J., Bolton, J., 1999. Physicochemical and structural characterization of alkali soluble lignins from oil palm trunk and empty fruitbunch fibers. J. Agric. Food Chem. 47, 2930-2936.

Sun, X.F., Sun, R.C., Fowler, P., Baird, M.S., 2005. Extraction and characterization of original lignin and hemicelluloses from wheat straw. J. Agric. Food Chem. 53, $860-870$.

Takahama, U., Oniki, T., Shimokawa, H., 1996. A possible mechanism for the oxidation of sinapyl alcohol by peroxidase-dependent reactions in the apoplast: enhancement of the oxidation by hydroxycinnamic acids and components of the apoplast. Plant Cell Physiol. 37, 499-504.

Tappi, 2004. 2004-2005 TAPPI Test Methods. TAPPI Press, Norcoss, GA, USA.

Vanholme, R., Morreel, K., Ralph, J., Boerjan, W., 2008. Lignin engineering. Curr. Opin. Plant Biol. 11, 278-285.

Zhang, L., Gellerstedt, G., 2001. NMR observation of a new lignin structure, a spirodienone. Chem. Commun., 2744-2745.

Zhang, L., Gellerstedt, G., 2004. Observation of novel $\beta-\beta$ structures in native lignin by high resolution 2D NMR techniques. In: Proceedings of the 8th European Workshop Lignocellulosics and Pulp, Riga, 22-25 August 2004, Latvian State Institute of Wood Chemistry, pp. 275-278.

Zhang, L.M., Gellerstedt, G., 2007. Quantitative 2D HSOC NMR determination of polymer structures by selecting suitable internal standard references. Magn. Reson. Chem. 45, 37-45.

Zhang, L.M., Henriksson, G., Gellerstedt, G., 2003. The formation of $\beta-\beta$ structures in lignin biosynthesis - are there two different pathways? Org. Biomol. Chem. 1, 3621-3624. 